\title{
Child Care Subsidies with One- and Two-Parent Families
}

\author{
Emily Moschini *
}

JOB MARKET PAPER

December 22, 2018

CLICK HERE FOR LATEST VERSION

\begin{abstract}
The implementation of child care subsidies has varied widely across countries and states, as well as over time, ranging from universal to poverty-tested eligibility. I study the implications of eligibility rules for child care subsidies in a general equilibrium, overlapping generations framework where altruistic parents invest in child skill. I allow for one- and two-parent families, and endogenize family formation with a marriage market. This explicitly incorporates single mothers, who currently parent $20 \%$ of children under 5 in the United States. Using individual-level data from the US Department of Education, I estimate how mother time, father time, and non-parental child care affect child skill for each family structure. These estimates allow me to account for the differential effect of child care subsidies on one- and two-parent families. My general equilibrium framework accounts for the effect of the subsidy on government expenditures as well as the skill distribution and, through that, on endogenous tax rates. I find that universal subsidies yield ex ante welfare gains of 5.9 percentage points, while targeting child care subsidies to one-parent families or poor families yields welfare gains of 2.4 and 2.0 percentage points, respectively. Universal subsidies more fully insure newborns against the risks they face than targeted subsidies, and do not disincentivize skill investment as happens with subsidies to the poor.
\end{abstract}

${ }^{*}$ Department of Economics, University of Minnesota. email: mosch019@umn.edu. Acknowledgements: I am indebted to my thesis advisors Ellen McGrattan, Loukas Karabarbounis, and Joseph Mullins for their guidance and support, as well as Anmol Bhandari, Jeremy Lise, and Arthur Rolnick for their thoughtful advice. I would also like to thank participants in the Minnesota Macro Workshop at the University of Minnesota, Sergio Ocampo Diaz, Sergio Salgado Ibanez, David Olsen, and Dominic Smith for helpful discussions and comments. All errors are mine. 


\section{Introduction}

Large-scale subsidized child care programs have been implemented around the world. ${ }^{1}$ These large-scale programs are built on the success of smaller programs, which provided enriched early childhood environments for children from poor families and have shown potentially major gains from public intervention. ${ }^{2}$ Empirical evaluations of large-scale child care subsidies have uncovered heterogeneous treatment effects along the dimensions of family income, family structure, and child gender, with conclusions differing by the country or state whose program is being evaluated. ${ }^{3}$ Designs of these programs vary, but eligibility is usually universal or means-tested (targeted to poor families).

In this paper, I pursue a structural macroeconomic approach to analyze large-scale child care subsidies in the United States. The approach allows me to transcend local confounding factors, acknowledge general equilibrium effects on wages, the government budget, and marriage, and to evaluate policy designs that have not been already implemented. Specifically, I examine child care subsidies under three eligibility rules: universal, subsidies to the poor, and subsidies to one-parent families. To do this, I construct a general equilibrium overlapping generations model with families that are heterogeneous in income and marital status. My model takes into account endogenous family formation and altruistic parental investment in child skill (Becker and Tomes (1979)). The three eligibility rules I examine permit a meaningful comparison between a targeting rule a model like mine can evaluate and more commonly implemented policies. In my analysis, I focus on the distribution of welfare gains across gender, skill, marital status, and age.

Comparing these subsidies in general equilibrium allows me to incorporate adjustments in labor income taxes, wages, and marriage decisions in response to policy. This feedback can magnify or mitigate the gains from the subsidy. For example, increases in skill, if accompanied by much higher labor income taxes to fund those increases, may not raise disposable earnings, consumption, or welfare for some groups. This is the case under a subsidy targeted to the poor. Similarly,

\footnotetext{
${ }^{1}$ Examples include: Oklahoma (started in 1998), Quebec (1997), Argentina (1993), Norway (1975), and Denmark (1964).

${ }^{2}$ Two well-known examples are the Abecedarian Program and the Perry Preschool Program. See Anderson (2008), Garcia, Heckman, Leaf, and Prados (2016), and Baker (2011).

${ }^{3}$ Studies of large-scale child care subsidies include Baker, Gruber, and Milligan (2008), Gupta and Simonsen (2010), Berlinski, Galiani, and Gertler (2009), Havnes and Mogstad (2014), Kottelenberg and Lehrer (2017), Blau and Currie (2006).
} 
endogenizing wages allows changes in the aggregate stock of skill to affect its rate of return, while endogenizing the family formation decision allows policy to affect the mass and composition of one- and two-parent families raising children in the economy. In fact, I find that the marriage rate decreases under the two targeted subsidies I consider, but increases under a universal child care subsidy. The family formation channel in my model is similar to that of Abbott, Gallipolli, Meghir, and Violante (2018), who examines how college tuition subsidies can affect the composition of marriages in the economy, but who do not allow for single-parent families to exist in equilibrium. The baseline framework into which I incorporate and endogenize heterogeneous family structures has been used to analyze the interaction of policy and skill investment in many studies, including Restuccia and Urrutia (2004), Lochner and Monge-Naranjo (2011), Guner, Kaygusuz, and Ventura (2016), Gayle, Limor, and Soytas (2017), Daruich (2017), Caucutt and Lochner (2017), Abbott, Gallipolli, Meghir, and Violante (2018), and Lee and Seshadri (2018).

The subsidies I evaluate generate welfare gains by partially addressing the market failures of the environment I construct. This model has four main sources of welfare gains: it insures against a low initial skill for the child, against being born into a family with fewer resources, and against a poor outcome in a frictional marriage market. In addition, it partially addresses a fiscal externality to parental investments in their child's skill.

To be specific, all newborns face risk over their initial skill, because a low draw makes good outcomes in adulthood harder to achieve. Similarly, the risk of being born into a low-resource family matters because parents and children cannot contract with one another (Cunha and Heckman (2007)). The resources available to invest in the child are therefore determined by the parent's permanent income, not the child's permanent income. The government, however, can use child care subsidies to lower the price of parental investment in children's skill, and then tax the child's labor earnings when they are older. In this way a child care subsidy combined with a labor income tax mimics a contract the child and parent would like to make with each other. With regard to marriage market risk, child care subsidies can partly insure individuals against parenting alone or with a low-skill spouse by lowering the costs of being a parent. Finally, the fiscal externality arises from an endogenous labor income tax. Taxpayers cannot use individual contracts to encourage others to invest in their children, so that the tax base expands and the labor income tax can de- 
crease for everyone. A child care subsidy partially addresses this missing market by lowering the cost of investment in child skill, using funds contributed from everyone in the economy.

In my environment, one- and two-parent families invest in their children using distinct technologies. Because there is no existing estimation appropriate for my specification, I estimate these functions using a nationally representative panel dataset from the US Department of Education-the Early Childhood Longitudinal Study, Birth Cohort (ECLS-B). The ECLS-B is designed to be representative of the entire population of parents in the United States with 9-month-old children in 2001, and follows over 10,000 children from 9 months to kindergarten entry, recording their skill at 9 months, 2 years, 4 years, and 5 years of age. In addition to providing a rich source of information on the evolution of skill in young children, this survey is unique in its emphasis on the role of fathers in child development. For almost 1,000 couples over the first three waves of this survey, one can observe the couple's hourly wages, their distinct time investments in their children, and their use of non-parental child care as well as the child care price. For families with single mothers, the analogous sample contains about 500 families.

The panel nature of the ECLS-B allows me to control for fixed effects within a family when implementing the estimation of skill accumulation parameters. This accounts for unobserved and timeinvariant heterogeneity in parenting productivity, child attributes, and local environment that affect the relative productivites of parental time and child care for investment in skill. My model specification for two-parent families is related to the skill accumulation technology in Del Boca, Flinn, and Wiswall (2014), who use the Panel Study of Income Dynamics, Child Development Supplement (PSID CDS) to estimate a Cobb-Douglas technology for couples with one or two children with separate time inputs from the mother and the father. Like them, I find that fathers play a non-negligible role in the raising of young children. I provide a second estimation for single mothers, which allows a new comparison of the ways that one- and two-parent families interact with non-parental care. I find that the input composition of investments is not very sensitive to price changes, and that single mothers rely more on non-parental child care for investment than two-parent families do. Consequently, although the price of investment is sensitive to the price of child care for both one- and two-parent families, the estimation indicates that this sensitivity is higher for one-parent families. 
Using my framework to compare universal subsidies, subsidies to single mothers, and subsidies to poor families, I find that ex ante welfare for families in the baseline economy increases by $5.9 \%$, with a $70 \%$ universal subsidy. Subsidies to single mothers can only reach a level of $2.4 \%$ welfare gains ex ante (at an 85\% subsidy level), and poverty-tested subsidies provide a $2.0 \%$ gain (at an $85 \%$ subsidy level). Universal subsidies yield the highest welfare gains because they more fully insure newborns against the risks they face (which include both their initial skill and their family), without requiring an increase in the labor income tax in order to fund them. Subsidies to the poor disincentivize skill investment and require an increase in the labor income tax to balance the government budget; subsidies to single mothers, although they do not disincentivize skill investment, provide less insurance than universal subsidies.

This paper provides three main contributions. First, I incorporate both one- and two-parent families into an overlapping generations framework to analyze subsidies to investment in children's skill. Second, parallel to this heterogeneity in family structures, I introduce heterogeneity in the technologies that parents use to invest in their children, and provide estimates of these technologies. Finally, I allow the population to endogenously sort into the two structures via a marriage market, so that policy can affect the mass and composition of parents in one- and two-parent families.

The rest of the paper proceeds as follows. In section 2, I lay out the model. Section 3 presents the model parameterization, including the estimation of the skill accumulation technologies. Section 4 reports the subsidy design and level that maximizes ex ante welfare and interprets the distribution of welfare gains under each eligibility rule. Section 5 concludes.

\section{The Model}

There are four sets of agents in the economy: consumers, a representative firm, the government, and a non-parental child care provider. Consumers are grouped into families with either one or two parents, who altruistically invest in their child's skill with their own time and purchased child care time, as well as choosing consumption, savings, labor supply and leisure. The way time inputs affect children's skill is determined by a skill accumulation technology, which is indexed by 
the number of parents in the household. Given prices for labor and capital, the firm chooses labor and capital inputs to maximize profits subject to a free-entry condition. The government chooses labor income taxes to finance lump-sum transfers and non-parental child care subsidies. A child support system exists, enforced by the government, where single fathers contribute a lump-sum amount that is redistributed lump-sum and equally to all single mothers. Finally, the non-parental child care sector supplies child care at the amount demanded in equilbrium, at a price equal to some fraction of the average hourly wage.

\section{The Life Cycle of Consumers}

Each individual lives for four periods of equal length: childhood, parenthood, adult worker, and old worker. During childhood, an individual makes no decisions: she is a passive recipient of consumption and investment chosen by her family. Upon independence, the individual leaves with her skill to start the parenting phase as an independent decision maker.

At the beginning of the parenting phase, before any decisions are made, everyone participates in a marriage market. This market is modelled as a random search with an arrival rate of one: a potential match is drawn from the skill distribution of the other gender in the same generation. Once assigned a potential spouse, and knowing that fertility is exogenous and certain in the environment, the agent compares the expected present discount value of parenting alone or in a couple.

The gains from joining a couple are reflected by higher efficiencies in translating income into consumption (introduced with consumption equivalence scales) while the costs are reflected by the fact that spouses must compromise on time use. In addition, couples use the two-parent technology to invest in their children. Being a single parent, meanwhile, is an outside option to marriage that differs by gender. For a woman, single parenthood means that she keeps her children with her, using the one-parent technology to invest in them, and receives lump-sum child support transfers from single fathers. For a man, single parenthood means that he cannot directly affect his child's skill with his time use, but does have to pay a lump-sum child support tax to the single mother. ${ }^{4}$

\footnotetext{
${ }^{4}$ The outside option to parenting in a couple differs by gender in the model because, empirically, the vast majority of
} 
Whether parenting alone or in a couple, the lifetime utility of any individual contains a term that incorporates rational expectations about the lifetime utility of one's child. ${ }^{5}$ This expectation is taken over the initial skill of the child, which is drawn from an exogenous distribution and is unknown when the marriage decision is made. The predictive power of a child's initial skill for lifetime utility, however, endogenously responds to policy. This, along with the endogenous labor income tax, is the channel by which policy affects the family formation decision.

Once a potential couple has compared their two alternatives, a marriage requires that both the husband and wife accept the match (the two individuals remain single otherwise). After the marriage market, single mothers and couples draw the initial skill of their two children, which is the same for both children (single mothers and couples each raise both a son and a daughter). Given their beliefs about how skill affects lifetime utility, parents then choose the level and composition of investment in their children's skills. At the end of the parenting phase, the children leave their parents' state space, and parents enjoy an altruistic return from the lifetime utilities of their children.

The problems of the adult worker and the old worker periods differ only in that old workers die at the end of their phase, so in the last period of the old worker phase there is no savings decision. Before old age there are no borrowing constraints: borrowing constraints on the parents are not a source of market incompleteness in this model. To summarize, the shocks in the life of an individual are their own initial skill, their gender, the family that raises them, their potential spouse, and the draw of their children's initial skill. Figure 1 illustrates the timing of the phases and the draws of these shocks.

\footnotetext{
single parents who are raising young children in their home are women. For a discussion of what the ECLS-B offers in terms of discipline on contributions of parental time from single fathers, see the appendix.

${ }^{5}$ This is what makes parents altruistic. An alternative way of incentivizing intergenerational transfers is through paternalistic preferences, or "warm glow" returns (Andreoni (1990)). The benefit of motivating parents with altruism is that the returns to investment can respond rationally and endogenously to policy, because parents fully incorporate the economic returns to their investment in terms of their child's lifetime utility. The main benefit of a paternalistic specification is its tractability and flexibility in matching parenting behaviors. Some models combine the two, and include both altruism and a paternalistic preference for, say, college attainment which is distinct from its monetary returns. For an application of paternalistic preferences to intergenerational transfers of wealth, see De Nardi (2004).
} 
Figure 1: Life Cycle of the Consumer

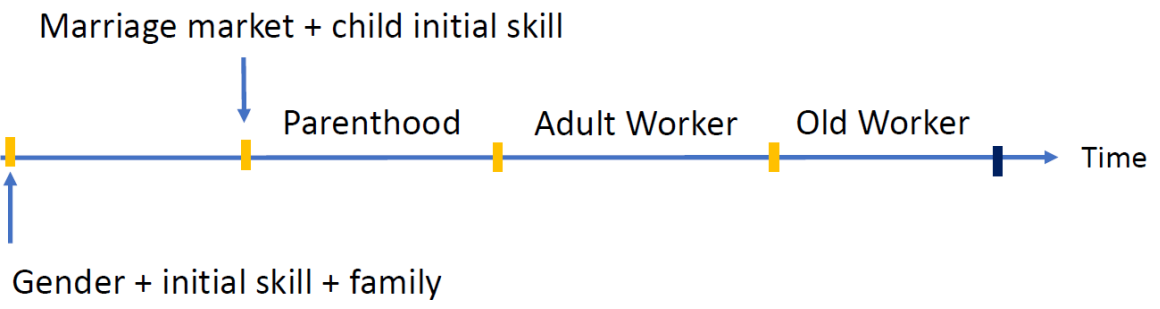

\section{One- and Two-Parent Families}

The two family structures are different in that they have different efficiencies of consumption $\left(\left\{\phi_{s}\right\}\right.$ and $\left\{\phi_{m c, p}, \phi_{m c, w}\right\}$, which are consumption equivalence scales) and are allowed to have different marginal utilities of leisure (which will be reflected in the parameters of the period utility functions $\left(u_{s}, u_{m c}\right)$, whose functional forms are defined in the model parameterization section). Married couples compromise on their leisure decision in the sense that it has to be the same for both members of the couple. They also use a skill accumulation technology specific to two-parent families to invest in their children $\left(f_{m c}\right)$. Similarly, single mothers invest in children using a skill technology specific to them $\left(f_{s}\right)$.

\section{Family Problems}

The solution to a family's life-cycle problem is a set of policy functions and value functions. These functions are defined for young adults (before the marriage decision) with skill $\theta$ and gender $g \in[1,2]$ where 1 is father and 2 is mother, and for one and two-parent families at each period $j \in\{1,2,3\}$ (with the numbers corresponding to parenthood, adult worker, and old worker, respectively), state $z$, and the skill of the single parent $\theta$ or the skills of the father $f$ and mother $m$ of the couple $\left(\theta_{f}, \theta_{m}\right)$. The state space $z$ always contains assets, which are zero at the start of life, and during parenthood also contains the initial skill of the child. The value functions are:

- For young adults: $V_{0}(\theta, g)$

- For single mothers: $V_{j}^{S M}(z ; \theta)$

- For single fathers: $V_{j}^{S F}(z ; \theta)$ 
- For married couples: $V_{j}^{M C}\left(z ; \theta_{f}, \theta_{m}\right)$

\section{The Marriage Decision and Probability of Getting Married}

The policy function that maps from the type of the spouse to a yes or no marriage market decision $\left(d_{m m}\left(\theta_{f}, \theta_{m}, g\right) \in\{0,1\}\right.$, given the skill $\theta_{m}$ or $\theta_{f}$ and gender $g$ of the decision maker), is a threshold strategy in the skill of the potential spouse. It solves:

$$
\begin{aligned}
& d_{m m}\left(\theta_{f}, \theta_{m}, 1\right)=\underset{\delta \in\{0,1\}}{\arg \max }\left[\delta \int_{\theta_{c}} V_{1}^{M C}\left(z ; \theta_{f}, \theta_{m}\right) \pi\left(\theta_{c}\right) d \theta_{c}+(1-\delta) \int_{\theta_{c}} V_{1}^{S F}\left(z ; \theta_{f}\right) \pi\left(\theta_{c}\right) d \theta_{c}\right] \\
& d_{m m}\left(\theta_{f}, \theta_{m}, 2\right)=\underset{\delta \in\{0,1\}}{\arg \max }\left[\delta \int_{\theta_{c}} V_{1}^{M C}\left(z ; \theta_{f}, \theta_{m}\right) \pi\left(\theta_{c}\right) d \theta_{c}+(1-\delta) \int_{\theta_{c}} V_{1}^{S M}\left(z ; \theta_{m}\right) \pi\left(\theta_{c}\right) d \theta_{c}\right]
\end{aligned}
$$

where $z=\left\{0, \theta_{c}\right\}$ is the state space in the first period of life which reflects the zero wealth all consumers start with and the initial skill of the child $\theta_{c}$, and the distribution of initial child skills has a probability density function given by $\pi\left(\theta_{c}\right)$.

\section{Draws for Marriage Offer, Partner Type, and Child Skill}

The expected lifetime utility of a child enters into the parent problem. It is an expectation over outcomes in the marriage market and draws of initial child skill when they become a parent, as a function of their skill and gender $g$ :

$$
\begin{aligned}
V_{0}\left(\theta_{f}, 1\right) & =\int_{\theta_{m}}\left[\mathbb{I}_{d} \int_{\theta_{c}} V_{1}^{M C}\left(z ; \theta_{f}, \theta_{m}\right) \pi\left(\theta_{c}\right) d \theta_{c}+\left(1-\mathbb{I}_{d}\right) \int_{\theta_{c}} V_{1}^{S F}\left(z ; \theta_{f}\right) \pi\left(\theta_{c}\right) d \theta_{c}\right] \mu\left(\theta_{m}, 2\right) d \theta_{m} \\
V_{0}\left(\theta_{m}, 2\right) & =\int_{\theta_{f}}\left[\mathbb{I}_{d} \int_{\theta_{c}} V_{1}^{M C}\left(z ; \theta_{f}, \theta_{m}\right) \pi\left(\theta_{c}\right) d \theta_{c}+\left(1-\mathbb{I}_{d}\right) \int_{\theta_{c}} V_{1}^{S M}\left(z ; \theta_{m}\right) \pi\left(\theta_{c}\right) d \theta_{c}\right] \mu\left(\theta_{f}, 1\right) d \theta_{f}
\end{aligned}
$$

where $\mathbb{I}_{d} \equiv d_{m m}\left(\theta_{f}, \theta_{m}, 1\right) \times d_{m m}\left(\theta_{f}, \theta_{m}, 2\right)$ indicates a mutual acceptance of the match, $z=\left\{0, \theta_{c}\right\}$ and $\theta_{c}$ is the child's initial skill, drawn independently from an exogenous distribution. In addition, $\mu(\theta, g)$ is the endogenous distribution over adult skill $\theta$ and gender $g$. In the following subsections, I define the life-cycle problem for each of the three family types: single mother, single father, and 
married parents. In all the family problems, $\tau_{y}$ is the labor income tax,$\tau_{n}$ is the child care subsidy, $T$ are lump-sum transfers, and $T_{c s}$ are child support payments.

\section{Single Mother Problem}

During parenthood, a single parent chooses consumption $c$, savings $a^{\prime}$, non-parental child care time $n$, her own time investments in her child $q$, and leisure $\ell$ to solve the following problem:

$$
\begin{aligned}
V_{1}^{S M}\left(a, \theta_{c} ; \theta\right) & =\max _{c, a^{\prime}, n, q, \ell} u_{s}\left(\frac{c}{\phi_{s}}, \ell\right)+\beta V_{2}^{S M}\left(a^{\prime} ; \theta\right)+b \sum_{g} V_{0}\left(\theta_{c}^{\prime}, g\right) \\
c+a^{\prime}+\left(1-\tau_{n}\right) p_{n} n \leq & (1+r) a+\left(1-\tau_{y}\right) w \theta(1-\ell-q)+T+T_{c s} \\
\ell, n, q \in[0,1] \quad & \ell+q \leq 1 \quad n+q \leq 1 \\
\theta_{c}^{\prime}= & f_{s}\left(\theta_{c}, n, \theta q\right)
\end{aligned}
$$

Here, and in what follows, $\phi_{s}$ is the consumption-equivalence scale for single-parent families with children, $\beta$ is the discount factor (patience), $b$ is the altruism parameter, $w$ denotes the wage rate, and $p_{n}$ denotes the price of non-parental child care. During the parenting phase, parental and non-parental child care time investments in child skill affect skill in the next period according to the single parent production technology. The final child skill enters the objective function of the mother through an altruism term $b \sum_{g} V_{0}\left(\theta_{c}^{\prime}, g\right)$, which weights the expected lifetime utility of the child $V_{0}\left(\theta_{c}^{\prime}, g\right)$ with the altruism coefficient $b$. Throughout their childhood, the mother cannot direct investments separately to the son and daughter. Her children are born with the same skill and receive the same investments. For a regression motivating this assumption, see the appendix. During the adult worker phase, the single mother consumes $c$, saves $a^{\prime}$, and enjoys leisure $\ell$ :

$$
\begin{aligned}
V_{2}^{S M}(a ; \theta) & =\max _{c, a^{\prime}, \ell} u_{s}(c, \ell)+\beta V_{3}^{S M}\left(a^{\prime} ; \theta\right) \\
c+a^{\prime} & \leq(1+r) a+\left(1-\tau_{y}\right) w \theta(1-\ell)+T \\
\ell & \in[0,1]
\end{aligned}
$$

During the old worker phase, the single mother consumes $c$, and enjoys leisure $\ell$. She dies with zero savings: 


$$
\begin{aligned}
V_{3}^{S M}(a ; \theta) & =\max _{c, \ell} u_{s}(c, \ell) \\
c & \leq(1+r) a+\left(1-\tau_{y}\right) w \theta(1-\ell)+T \\
\ell & \in[0,1]
\end{aligned}
$$

\section{Single Father Problem}

During parenthood, a single father chooses consumption $c$, savings $a^{\prime}$, and leisure $\ell$ to solve the following problem. They also have to pay child support $T_{c s}$ which is received by single mothers:

$$
\begin{aligned}
V_{1}^{S F}(a ; \theta) & =\max _{a^{\prime}, c, \ell} u_{s}(c, \ell)+\beta V_{2}^{S F}\left(a^{\prime} ; \theta\right)+\zeta(\mu) \\
\ell & \in[0,1] \\
c+a^{\prime}+T_{c s} & \leq(1+r) a+\left(1-\tau_{y}\right) w \theta(1-\ell)+T
\end{aligned}
$$

Single fathers do not internalize their child's outcome directly; rather, their payoff includes some function of the aggregate endogenous state $\zeta(\mu)$, which I will specificy in the parameterization section. This specification allows policy to affect single fathers through the distribution of skill $\mu$. This specification also does not allow a single father to use his own time to invest in his children. I start from the assumption that resident fathers are more able to invest in their children's skill with their own time than non-resident fathers. Here, I take that assumption to an extreme and abstract from single father time investments entirely, as well breaking the link between the objective function of the single father and the specific outcomes of their children.

During the adult worker phase, single fathers consume $c$, save $a^{\prime}$, and enjoy leisure $\ell$ by solving the following problem:

$$
\begin{aligned}
V_{2}^{S F}(a ; \theta)= & \max _{c, a^{\prime}, \ell} u_{s}(c, \ell)+\beta V_{3}^{S F}\left(a^{\prime} ; \theta\right) \\
c+a^{\prime}= & (1+r) a+\left(1-\tau_{y}\right) w \theta(1-\ell)+T \\
& \ell \in[0,1]
\end{aligned}
$$

During the old worker phase, the single father consumes $c$ and enjoys leisure $\ell$. He dies with zero 
savings:

$$
\begin{aligned}
V_{3}^{S M}(a ; \theta) & =\max _{c, \ell} u_{s}(c, \ell) \\
c & \leq(1+r) a+\left(1-\tau_{y}\right) w \theta(1-\ell)+T \\
\ell & \in[0,1]
\end{aligned}
$$

\section{Married Couple Problem}

During the parenting phase, married couples choose consumption $c$, savings $a^{\prime}$, leisure $\ell$, nonparental child care time $n$ and parental time inputs $\left\{q_{f}, q_{m}\right\}$. Like single mothers, married couples cannot direct investment by child gender and enjoy an altruistic return from the lifetime utility of their children as a function of their skill at adulthood.

$$
\begin{aligned}
V_{1}^{M C}\left(a, \theta_{c} ; \theta_{f}, \theta_{m}\right) & =\max _{c, a^{\prime}, \ell, n, q_{f}, q_{m}} u_{m c}\left(\frac{c}{\phi_{m c, p}}, \ell\right)+\beta V_{2}^{M C}\left(a^{\prime}, \theta_{c}^{\prime} ; \theta_{f}, \theta_{m}\right)+b \sum_{g_{\text {child }}} V_{0}\left(\theta_{c}, g\right) \\
c+a^{\prime}+\left(1-\tau_{n}\right) p_{n} n \leq & (1+r) a+\left(1-\tau_{y}\right) w\left[\theta_{f}\left(1-\ell-q_{f}\right)+\theta_{m}\left(1-\ell-q_{m}\right)\right]+T \\
\ell, n, q_{f}, q_{m} \in[0,1] \quad & \ell+q_{f} \leq 1 \quad \ell+q_{m} \leq 1 \quad n+q_{f}+q_{m} \leq 1 \\
\theta_{c}^{\prime} & =f_{m c}\left(\theta_{c}, n, \theta_{f} q_{f}, \theta_{m} q_{m}\right)
\end{aligned}
$$

Here, $\phi_{m c, p}$ is the consumption-equivalence scale of a family with two adults and two children. The specification I use for the married couple problem is based on Guvenen and Rendall (2015). As in that study, I motivate the perfect complementarity in leisure of the spouses with time use data as documented in Aguiar and Hurst (2007), Table V. However, unlike Guvenen and Rendall (2015), I do not make the marginal utility of leisure stochastic. In my model, by comparison, the only source of risk in marriage is the initial skill of the children the couple has together.

During the adult worker phase, married couples consume $c$, save $a^{\prime}$, and enjoy leisure $\ell$ :

$$
\begin{aligned}
V_{2}^{M C}\left(a ; \theta_{f}, \theta_{m}\right) & =\max _{c, a^{\prime}, \ell} u_{m c}\left(\frac{c}{\phi_{m c, w}}, \ell\right)+\beta V_{3}^{M C}\left(a^{\prime} ; \theta_{f}, \theta_{m}\right) \\
c+a^{\prime} & \leq(1+r) a+\left(1-\tau_{y}\right) w\left[\theta_{f}\left(1-\ell-q_{f}\right)+\theta_{m}\left(1-\ell-q_{m}\right)\right]+T \\
\ell & \in[0,1]
\end{aligned}
$$


Here, $\phi_{m c, w}$ is the consumption-equivalence scale of a family with two adults and two children. During the old worker phase married couples consume $c$ and enjoys leisure $\ell$. They die with zero savings:

$$
\begin{aligned}
V_{3}^{M C}\left(a ; \theta_{f}, \theta_{m}\right) & =\max _{c, \ell} u_{m c}\left(\frac{c}{\phi_{m c, w}}, \ell\right) \\
c & \leq(1+r) a+\left(1-\tau_{y}\right) w\left[\theta_{f}\left(1-\ell-q_{f}\right)+\theta_{m}\left(1-\ell-q_{m}\right)\right]+T \\
\ell & \in[0,1]
\end{aligned}
$$

\section{Government}

The government collects revenue from labor income taxes $\tau_{y}$ to finance lump-sum transfers $T$ and non-parental child care subsidies $\tau_{n}$. The variable $H$ is the aggregate supply of labor efficiency units, and $N$ is the aggregate demand for non-parental child care:

$$
\tau_{y} w H=T+\tau_{n} p_{n} N
$$

\section{Representative Firm}

The firm chooses capital $K_{F}$ and labor inputs $H_{F}$ to maximize profits, taking prices $r$ and $w$ as given. The parameter $\delta_{F}$ is the depreciation rate of capital.

$$
\max _{K, H}\left\{K_{F}^{\alpha_{F}} H_{F}^{1-\alpha_{F}}-w H_{F}-\left(r+\delta_{F}\right) K_{F}\right\}
$$

\section{Non-parental Care Sector}

The non-parental child care sector provides $N$ units of non-parental child care at price $p_{n}$. The price of non-parental child care is set as a constant fraction $\kappa$ of the average earnings per unit of time:

$$
p_{n}=\kappa \sum_{g} \int_{\theta} w \theta \mu(\theta, g) d \theta
$$


This allows the price of non-parental child care to adjust with the average level of skill in the economy, but without specifying a production function for non-parental child care.

\section{Equilibrium}

Given a government policy $\left\{\tau_{n}\right\}$, transfers $T$, and child support $T_{c s}$, a stationary equilibrium is defined as:

- Prices $\{r, w\}$ and tax $\tau_{y}$,

- Individual marriage decision rules for each type and potential spouse,

- Policy functions for each family type for each period of life $j$ and state $z$,

- Value functions at the beginning of adulthood $V_{0}$ and for each family type $V^{S M}, V^{S F}, V^{M C}$,

- A non-parental child care price $p_{n}$,

- Joint distribution $\mu$ over adult skill and gender,

such that:

- Capital and labor markets clear.

- The government balances its budget taking prices as given.

- Family decision rules solve their dynamic problems taking prices and taxes as given.

- The non-parental child care price $p_{n}$ is a constant fraction $\kappa$ of average hourly earnings.

- The joint distribution $\mu$ is stationary.

\section{Market Incompleteness in the Environment}

As I discuss in the introduction, the subsidies I evaluate generate welfare gains by partially addressing the market failures of the environment I construct. A child care subsidy in this environment yields welfare gains from four main sources: it insures against a low initial skill for the child, 
against being born into a family with fewer resources, and against a poor outcome in a frictional marriage market. In addition, it partially addresses a fiscal externality to parental investments in their child's skill.

To be specific, all newborns face risk over their initial skill, because a low draw makes good outcomes in adulthood harder to achieve. Similarly, the risk of being born into a low-resource family matters because parents and and children cannot contract with one another (Cunha and Heckman (2007)). The resources available to invest in the child are therefore determined by the parent's permanent income, not the child's permanent income. The government, however, can use child care subsidies to lower the price of parental investment in children's skill, and then tax the child's labor earnings when they are older. In this way a child care subsidy combined with a labor income tax mimics a contract the child and parent would like to make with each other. With regard to marriage market risk, child care subsidies can partly insure individuals against parenting alone or with a low-skill spouse by lowering the costs of being a parent. Finally, the fiscal externality arises from an endogenous labor income tax. Taxpayers cannot use individual contracts to encourage others to invest in their children, so that the tax base expands and the labor income tax can decrease for everyone. A child care subsidy partially addresses this missing market by lowering the cost of investment in child skill, using funds contributed from everyone in the economy.

When I analyze the results of the policy experiment I conduct, I discuss how different specifications would affect the magnitude of welfare gains. In particular, I find that universal subsidies yield the highest welfare gains. This is in part because in this environment, there is risk over the initial skill of the child which is distinct from the equilibrium distribution of families and unaffected by policy (because the distribution of initial skill is exogenous). This makes a universal subsidy yield higher welfare gains than it would in an environment where everyone was born with the same initial skill or where the distribution of initial skill was endogenous.

\section{Model Parameterization}

To implement this model, I grouped the model parameters into those chosen externally, those estimated outside the model, and those calibrated inside the model. Parameters chosen externally 
are drawn from the literature, or using a common rule. Parameters estimated outside the model refers to the set of parameters that I discipline with data, but for which I do not have to solve for the model equilibrium to check how the model moment compares with the moment in the data. These include the skill accumulation technology parameters, among others, which are estimated using first-order conditions of the parenting problems (I will explain this estimation in more detail further on in this section). Finally, the set of parameters calibrated inside the model refers to those parameters for which I have to solve for the model equilibrium in order to generate a model moment to compare with the data. These parameters include the altruism coefficient $b$, the productivity of investment $\lambda$, and the marginal utility of leisure for singles $\left(\psi_{s}\right)$ and couples $\left(\psi_{m c}\right)$.

\subsection{Functional Form Assumptions}

\section{Period Utility Functions}

Utility functions are defined separately for one- and two-parent families:

$$
u_{\text {type }}(c, \ell)=\log (c)+\psi_{\text {type }} \log (\ell), \quad \text { type } \in\{s, m c\}
$$

\section{Single Father Altruism Term}

I set the single father term $\zeta(\mu)$ equal to the minimum possible outcome in the economy:

$$
\zeta(\mu)=\min _{\theta, g} V_{0}(\theta, g)
$$

In practice, reasonable values for child support transfers (see appendix) are not sufficient to reach the targeted marriage rate in the internal calibration without further penalizing the single father path. With this specification, I still make the single father lifetime utility depend directly on the skill distribution in the economy, as with the other parenting problems. By comparison, using the average outcome does not sufficiently penalize the single father. 


\section{Distribution of Initial Child Skill}

I assume that initial child skill is drawn independently and identically from $\pi\left(\theta_{c}\right)$, which I set as a uniform distribution. For motivating regressions for the i.i.d. assumption, see the appendix.

\section{Skill Accumulation Technologies}

I specify the skill accumulation technologies to be nested constant elasticity of substitution (CES) functions with inputs of non-parental time, mother time, and father time (which aggregate to investment $I_{\text {type }}$ ) and between investment and the current stock of skill (which aggregate to tomorrow's skill). Specifically, the functional forms of the dynamic equation for skill accumulation, and how investment is generated from time inputs for the two family structures, are as follows:

$$
\begin{aligned}
f_{\text {type }}(\cdot) & =\left[v\left(\lambda I_{\text {type }}\right)^{\xi}+(1-v) \theta_{c}^{\xi}\right]^{\frac{1}{\xi}}, \quad \text { type } \in\{s, m c\} \\
I_{s} & =\left[\gamma_{s}\left(\theta_{m} q_{m}\right)^{\eta_{s}}+\left(1-\gamma_{s}\right)(n)^{\eta_{s}}\right]^{\frac{1}{\eta_{s}}} \\
I_{m c} & =\left[(1-\alpha)\left(\gamma\left(\theta_{m} q_{m}\right)^{\eta}+(1-\gamma)(n)^{\eta}\right)^{\frac{\rho}{\eta}}+\alpha\left(\theta_{f} q_{f}\right)^{\rho}\right]^{\frac{1}{\rho}}
\end{aligned}
$$

The parameters $\gamma, \gamma_{s}$ and $\alpha$ control the relative level of inputs given a price ratio. The values of $\eta, \eta_{s}$, and $\rho$ control the percentage change in the ratio of inputs for a percentage change in the ratio of their prices. With this parameterization, I allow for mother time and non-parental child care time to interact differently across household structures (i.e., I do not impose $\gamma=\gamma_{s}$ and $\eta=\eta_{s}$ ). ${ }^{6}$

\subsection{Externally Chosen Parameters}

The length of a lifetime and of each phase are proportional to 20 years of childhood and 60 years of adulthood (death at age 80). The discount (patience) factor is set to a yearly value of 0.96 to match the risk-free interest rate. The capital share of the production technology is set to a standard value of 0.33 , and the depreciation rate of capital is chosen to be 1 . Finally, the consumption equivalence (CE) scales are set using the 1994 scales from the Organisation for Economic Co-

\footnotetext{
${ }^{6} \mathrm{~A}$ different and common way of specifying the investment aggregator is to include money (goods) and parental time inputs. See the appendix for an exercise where I measure the contribution of child care costs to expenditures on children in different age groups, using the 2001 PSID and the 2002 PSID CDS. I find that child care costs are a sizeable compoenent of money spent on children by any measure of spending on children I consider (the share ranges from 50 to 70 percent of total spending). My specification makes explicit how expenditures on children affect child skill accumulation through child time use.
} 
operation and Development (OECD). These scales assign a value of 1 for the first adult, and 0.5 for the subsequent adults; for each dependent the weight is 0.3. They adjust money spent on consumption into units of consumption for each member of the household. Once children leave the family, the equivalence scale for single mothers goes back to 1, and the scale for couples falls to 1.5 . This is summarized in Table 1.

Table 1: Externally Chosen Parameters

\begin{tabular}{lcc}
\multicolumn{1}{c}{ Symbol } & Name & Value \\
\hline$\beta$ & Patience & $0.96^{20}$ \\
$\left\{\alpha_{F}, \delta_{F}\right\}$ & Production Technology & $\{0.33,1\}$ \\
$\left\{\phi_{s}\right\}$ & OECD CE Scales: 1 adult, 2 children & $\{1.6\}$ \\
$\left\{\phi_{m c, p}, \phi_{m c, w}\right\}$ & OECD CE Scales: 2 adult, 2 children & $\{2.1,1.5\}$ \\
\hline
\end{tabular}

\subsection{Estimation of Skill Accumulation Technologies}

In this section, I explain how I estimate the parameters of the skill technology from the ECLS$\mathrm{B}$ dataset. The panel nature of the data allows me to use a fixed-effects estimator to control for heterogeneous productivity shifters on parental time inputs. The equations that I use to estimate the skill accumulation technology parameters are derived from the first order conditions of the parenting problem with respect to the quality time of the father and mother, and non-parental child care time. I assume that the aggregator of maternal time and non-parental time is the same functional form for both single mothers and married couples. Married couples differ from single mothers because of the time contribution of the father, which is modelled as an outer aggregator of father time and maternal/non-parental time. After taking first order conditions of the parenting problem with respect to the time investment choices, I take ratios of those equations and then logs. The result is a system of four linear equations. After deriving these equations with model notation, I explain how the objects in my model map into variables in the ECLS-B and motivate my use of the fixed effects estimator. I then provide the estimation equations in terms of observed variables in the ECLS-B. My derivation of the estimation equations is similar to the method of Lee and Seshadri (2018). 


\subsubsection{Estimation Equations}

The equations for the investment aggregators of singles and couples are given by (18) and (19). The partial derivatives of these equations enter the first order conditions of the parenting problem with respect to $q$ and $n$ for single mothers and $q_{m}, q_{f}$ and $n$ for married couples. After taking ratios and then logs of these first order conditions, I get the following linear equations, one for single mothers and two for married couples. It is apparent that the parenting productivities can be separated linearly from the terms of interest.

$$
\begin{aligned}
\ln \left(\frac{q}{n}\right) & =\left(\frac{1}{\eta_{s}-1}\right) \ln \left[\frac{w \theta}{\left(1-\tau_{n}\right) p_{n}}\right]+\left(\frac{1}{\eta_{s}-1}\right) \ln \left[\frac{1-\gamma_{s}}{\gamma_{s}}\right]-\left(\frac{\eta_{s}}{\eta_{s}-1}\right) \ln (\theta) \\
\ln \left(\frac{q_{m}}{n}\right) & =\left(\frac{1}{\eta-1}\right) \ln \left[\frac{w \theta_{m}}{\left(1-\tau_{n}\right) p_{n}}\right]+\left(\frac{1}{\eta-1}\right) \ln \left[\frac{1-\gamma}{\gamma}\right]-\left(\frac{\eta}{\eta-1}\right) \ln \left(\theta_{m}\right) \\
\ln \left(\frac{q_{f}}{n}\right) & =\left(\frac{1}{\rho-1}\right) \ln \left[\frac{w \theta_{f}}{\left(1-\tau_{n}\right) p_{n}}\right]+\left(\frac{\eta-\rho}{\eta(\rho-1)}\right) \ln \left(\frac{q_{m}}{n} \frac{w \theta_{m}}{\left(1-\tau_{n}\right) p_{n}}+1\right) \\
& +\left(\frac{1}{\rho-1}\right) \ln \left[\frac{(1-\alpha)}{\alpha(1-\gamma)^{\frac{\rho}{\eta}}}\right]-\left(\frac{\rho}{\rho-1}\right) \ln \left(\theta_{f}\right)
\end{aligned}
$$

In the first equation $q$ and $n$ are the quality time and non-parental child care time chosen by single mothers, respectively, $w \theta$ is the hourly wage of single mothers, $p_{n}$ is the price of non-parental child care, and $\theta$ is the parenting productivity of single mothers. In the second and third equations, $q_{m}, q_{f}$, and $n$ are the quality time inputs of mothers and fathers and the non-parental child care time chosen by married couples, $w \theta_{m}$ is the hourly wage of the mother, $w \theta_{f}$ is the hourly wage of the father, $p_{n}$ is the price of non-parental child care time, and $\theta, \theta_{m}, \theta_{f}$ are the parenting productivites of single mothers, married mothers, and married fathers, respectively.

To derive estimation equations for the skill aggregator equation (17), I impose intertemporal cost minimization, similar to the approach of Lee and Seshadri (2018). This means that I assume parents set the ratio of the marginal costs of investment (the prices of investment in each period, as derived above) equal to the ratio of marginal productivities of investment in each period, appropriately discounting the costs using interest rates. The result of the following steps will be an equation that expresses the ratio of expenditures over two consecutive periods on the left-hand 
side, and the ratio of investment prices over two consecutive periods on the right-hand side. First, I explain how I derive the price of skill investment for single and married couples. Second, I construct the equation I will use to estimate parameters $v$ and $\xi$ in equation (17).

The total expenditures on investment, $X_{t y p e, j}$, is the sum of foregone earnings and non-parental child care costs for the time invested in the child. For each family type, the expression for this cost is:

$$
\begin{aligned}
X_{s} & =\left(1-\tau_{n}\right) p_{n} n+w \theta q_{m} \\
X_{m c} & =\left(1-\tau_{n}\right) p_{n} n+w \theta_{f} q_{f}+w \theta_{m} q_{m}
\end{aligned}
$$

Investment expenditures purchase investment input into skill accumulation at a price $\Lambda_{\text {type }}$ :

$$
X_{\text {type }}=\Lambda_{\text {type }} I_{\text {type }}
$$

An analytical expression for the price of investment $\Lambda_{\text {type }}$ can be derived by taking the ratio of $X_{\text {type }}$ and $I_{\text {type }}$. The solution will be a function of parental skill and the prices of inputs, which are values the parent takes as given in this model.

For couples, the price of investment $\Lambda_{m c}$ is:

$$
\Lambda_{m c}=\frac{\left(1-\tau_{n}\right) p_{n}+w \theta_{f} \frac{1}{\theta_{f}} \Psi_{2, m c}+w \theta_{m} \frac{1}{\theta_{m}} \Psi_{1, m c}}{\Psi_{4, m c}}
$$

where

$$
\begin{aligned}
\Psi_{1, m c} & \equiv\left[\frac{w \theta_{m}}{\left(1-\tau_{n}\right) p_{n}} \frac{(1-\gamma)}{\gamma} \frac{1}{\theta_{m}}\right]^{\frac{1}{\eta-1}} \\
\Psi_{2, m c} & \equiv\left[\frac{1}{\theta_{f}} \frac{(1-\alpha)(1-\gamma)}{\alpha} \frac{w \theta_{f}}{\left(1-\tau_{n}\right) p_{n}}\left(\Psi_{3, m c}\right)^{\rho-\eta}\right]^{\frac{1}{\rho-1}} \\
\Psi_{3, m c} & \equiv\left(\gamma\left(\Psi_{1, m c}\right)^{\eta}+1-\gamma\right)^{\frac{1}{\eta}} \\
\Psi_{4, m c} & \equiv\left[\alpha\left(\Psi_{2, m c}\right)^{\rho}+(1-\alpha)\left(\Psi_{3, m c}\right)^{\rho}\right]^{\frac{1}{\rho}}
\end{aligned}
$$

For single mothers, the price of investment $\Lambda_{s}$ is: 


$$
\Lambda_{s}=\frac{\left(1-\tau_{n}\right) p_{n}+w \theta \frac{1}{\theta} \Psi_{1, s}}{\Psi_{2, s}}
$$

where

$$
\begin{aligned}
\Psi_{1, s} & =\left[\frac{1}{\theta} \frac{\left(1-\gamma_{s}\right) w \theta}{\gamma_{s}\left(1-\tau_{n}\right) p_{n}}\right]^{\frac{1}{\eta_{s}-1}} \\
\Psi_{2, s} & \equiv\left(\gamma_{s}\left(\Psi_{1, s}\right)^{\eta_{s}}+1-\gamma_{s}\right)^{\frac{1}{\eta_{s}}}
\end{aligned}
$$

The assumption of intertemporal cost minimization implies that for two consecutive observations in the data $t-1$ and $t$, the ratio of the marginal prices of investment equals the ratio of marginal productivities of that investment. Notice that here I am allowing childhood to have multiple periods as in the data, while in my model I assume it is a single period. This is why I have shifted from using $j$ to index age in the model to using $t$ to reference the period in the data. In this sense, my estimates of the skill accumulation technology parameters are quasi-structural. Now, for the objects $\theta_{c}, X_{\text {type }}, I_{\text {type, }}$ and $\Lambda_{\text {type, }}$ I add a time subscript $t$ or $t-1$.

$$
\frac{\left(\frac{1}{1+r_{t}}\right) \Lambda_{t y p e, t}}{\left(\frac{1}{1+r_{t-1}}\right) \Lambda_{\text {type },-1}}=\frac{\frac{\partial \theta_{c, t+1}}{\partial I_{t y p e, t}}}{\frac{\partial \theta_{j+1}}{\partial I_{t y p e, j-1}}}
$$

where type $\in\{s, m c\}$. Substituting $\frac{X_{t y p e, t}}{\Lambda_{\text {type,t }}}$ for $I_{\text {type }, t}$ and taking logs of both sides of the above equation gives a linear equation with the ratio of investment expenses on the left-hand side and the ratio of prices on the right-hand side:

$$
\ln \left(\frac{X_{\text {type }, t}}{X_{\text {type }, t-1}}\right)=\frac{1}{\xi-1} \ln [1-v]+\frac{\xi}{\xi-1} \ln \left(\frac{\Lambda_{\text {type }, t}}{\Lambda_{\text {type }, t-1}}\right)+\frac{1}{\xi-1} \ln \left[\frac{1+r_{t}}{1+r_{t-1}}\right]
$$

To control for the last term, which is a ratio of interest rates across periods, I assume a yearly interest rate of $4 \%$ (consistent with the risk-free rate that gives the discount factor $\beta$ ) and adjust the values $1+r_{t}$ in each period $t$ to be proportional to its distance from 0 , the period when the child is born. This means that at age 9 months, the first wave of the survey, the interest rate is $\frac{3}{4} \times(1.04)$, while in the second wave of the survey (when the child is 2 years old) this value is $2 \times(1.04)$. 
Notice that this last equation does not contain an additive constant that is cancelled out by a fixed effects estimator. Note also that I did not cancel parenting and labor market productivities in the definitions of $\Lambda_{\text {type }}$, in order to make the mapping from the model to the data more straightforward in the next section. When constructing prices, I recover the parenting productivity from the fixed effects estimations used to find the values of $\eta, \gamma, \eta_{s}$, and $\gamma_{s}$. I use those family-level values to build the price of investment at the family level in each period $t$.

Mapping Model Objects to Objects in the Data In the data section below, I explain in detail the procedure I use to prepare the ECLS-B data for estimation. After applying the procedure I describe there, I observe the following attributes of family $i$ in wave $t$ : hourly wages $\tilde{w}_{i, f, t}, \tilde{w}_{i, m, t}$ for father $f$ or mother $m$, hourly price of child care $\tilde{p}_{i, t}$ (which differs across families and across waves), quantity of child care purchased $\tilde{n}_{i, t}$ in units of hours per week, and hours of quality time contributed by the father $f$ and the mother $m: \tilde{q}_{i, f, t}, \tilde{q}_{i, m, t}$. Here I also put the $m$ subscripts on the single mother variables in the data, which is a departure from the model notation.

For couples, I estimate $\eta$ and $\gamma$ first, and then predict the ratio of mother time and non-parental child care time at the family level (incorporating the fixed effect levels). This is then substituted into the right-hand side of the estimation equation for $\rho, \alpha$ with father time and non-parental child care time on the left-hand side. For the last estimation equation, I construct investment prices $\tilde{\Lambda}_{\text {type }, i, t}$ and expenditures $\tilde{X}_{\text {type,i,t }}$ for each family in each wave by using the analogous variables from the data in equations (26) and (27). Individual-level parenting productivities $\theta, \theta_{m}$, and $\theta_{f}$ are not observed in the ECLS-B. I assume that these are time-invariant but can vary across individuals. I denote these unobserved parenting productivities with $\tilde{\theta}_{i, m}$ for the mother and $\tilde{\theta}_{i, f}$ for the father. Rewriting the four equations derived in the previous sections using notation for variables in the ECLS-B yields: 


$$
\begin{aligned}
& \ln \left(\frac{\tilde{q}_{i, m, t}}{\tilde{n}_{i, t}}\right)=\left(\frac{1}{\eta_{s}-1}\right) \ln \left[\frac{\tilde{w}_{i, m, t}}{\tilde{p}_{i, t}}\right]+\left(\frac{1}{\eta_{s}-1}\right) \ln \left[\frac{1-\gamma_{s}}{\gamma_{s}}\right]-\left(\frac{\eta_{s}}{\eta_{s}-1}\right) \ln \left(\tilde{\theta}_{i, m}\right) \\
& \ln \left(\frac{\tilde{q}_{i, m, t}}{\tilde{n}_{i, t}}\right)=\left(\frac{1}{\eta-1}\right) \ln \left[\frac{\tilde{p}_{i, t}}{\tilde{w}_{i, m, t}}\right]+\left(\frac{1}{\eta-1}\right) \ln \left[\frac{1-\gamma}{\gamma}\right]-\left(\frac{\eta}{\eta-1}\right) \ln \left(\tilde{\theta}_{i, m}\right) \\
& \ln \left(\frac{\tilde{q}_{i, f, t}}{\tilde{n}_{i, t}}\right)=\left(\frac{1}{\rho-1}\right) \ln \left[\frac{\tilde{p}_{i, t}}{\tilde{w}_{i, f, t}}\right]+\left(\frac{\eta-\rho}{\eta(\rho-1)}\right) \ln \left(\frac{\tilde{q}_{i, m, t}}{\tilde{n}_{i, t}} \frac{\tilde{w}_{i, m, t}}{\tilde{p}_{i, t}}+1\right) \\
& +\left(\frac{1}{\rho-1}\right) \ln \left[\frac{(1-\alpha)}{\alpha(1-\gamma)^{\frac{\rho}{\eta}}}\right]-\left(\frac{\rho}{\rho-1}\right) \ln \left(\tilde{\theta}_{i, f}\right) \\
& \ln \left(\frac{\tilde{X}_{\text {type }, i, t}}{\tilde{X}_{\text {type }, i, t-1}}\right)=\frac{1}{\xi-1} \ln [1-v]+\frac{\xi}{\xi-1} \ln \left(\frac{\tilde{\Lambda}_{\text {type }, i, t}}{\tilde{\Lambda}_{\text {type }, i, t-1}}\right)-\frac{1}{\xi-1} \ln \left[\frac{1+r_{t}}{1+r_{t-1}}\right]
\end{aligned}
$$

Recovering the Parameters of Interest For estimation purposes, equations (30) to (33) are rewritten as:

$$
\begin{aligned}
\ln \left(\frac{\tilde{q}_{i, m, t}}{\tilde{n}_{i, t}}\right) & =\beta_{1,0}+\beta_{1,1} \ln \left[\frac{\tilde{w}_{i, m, t}}{\tilde{p}_{i, t}}\right]+\beta_{1,2} \ln \left[\theta_{i, m}\right]+\epsilon_{i, t} \\
\ln \left(\frac{\tilde{q}_{i, m, t}}{\tilde{n}_{i, t}}\right) & =\beta_{2,0}+\beta_{2,1} \ln \left[\frac{\tilde{w}_{i, m, t}}{\tilde{p}_{i, t}}\right]+\beta_{2,2} \ln \left[\theta_{i, m}\right]+\epsilon_{i, t} \\
\ln \left(\frac{\tilde{q}_{i, f, t}}{\tilde{n}_{i, t}}\right) & =\beta_{3,0}+\beta_{3,1} \ln \left[\frac{\tilde{w}_{i, f, t}}{\tilde{p}_{i, t}}\right]+\beta_{3,2} \ln \left(\frac{\widetilde{\tilde{q}_{i, m, t}}}{\tilde{n}_{i, t}} \frac{\tilde{w}_{i, m, t}}{\tilde{p}_{i, t}}+1\right)+\beta_{3,3} \ln \left[\theta_{i, f}\right]+\epsilon_{i, t} \\
\ln \left(\frac{\tilde{X}_{\text {type }, i, t}}{\tilde{X}_{\text {type }, i, t-1}}\right) & =\beta_{4,0}+\beta_{4,1} \ln \left(\frac{\tilde{\Lambda}_{t y p e, i, t}}{\tilde{\Lambda}_{\text {type }, i, t-1}}\right)+\beta_{4,2} \ln \left[\frac{1+r_{t}}{1+r_{t-1}}\right]+\epsilon_{i, t}
\end{aligned}
$$

In an Ordinary Least Squares (OLS) estimation, the assumption that the residual was uncorrelated with the regressors would be violated in equations (34) to (36) if parenting productivities and labor market productivity were correlated (unobserved parenting productivities would be absorbed into the residual). Consequently, in regressions (34) to (36) I use a fixed effects estimator, which controls for the time-invariant parenting productivities by subtracting out the family-level mean and adding back in the population mean. Values for the population mean are reported under an assumption about the population average of $\ln \left(\theta_{i}\right)$. Since the productivity of non-parental 
child care is normalized to 1 , this level assumption is equivalent to one about the distribution of the $\log$ of relative parent/non-parent productivities in the population. That is, I assume the population average of the logged relative parenting productivities is 0 . Given that I do not offer empirical discipline for this choice, I conduct several robustness checks in the appendix on the share parameters in the skill accumulation technologies.

The mapping from regression coefficients to the model's parameters is as follows:

$$
\begin{array}{r}
\gamma_{s}=\frac{1}{\exp \left(\frac{\beta_{1,0}}{\beta_{1,1}}\right)+1} \quad, \quad \eta_{s}=\frac{1}{\beta_{1,1}}+1 \\
\gamma=\frac{1}{\exp \left(\frac{\beta_{2,0}}{\beta_{2,1}}\right)+1} \quad, \quad \eta=\frac{1}{\beta_{2,1}}+1 \\
\alpha=\frac{1}{\frac{\exp \left(\frac{\beta_{3,0}}{\beta_{3,1}}\right)}{1-\gamma}+1} \quad, \quad \rho=\frac{1}{\beta_{3,1}}+1 \\
v=1-\exp \left(\frac{\beta_{4,0}}{\beta_{4,1}-1}\right) \quad, \quad \xi=\frac{\beta_{4,1}}{\beta_{4,1}-1}
\end{array}
$$

\subsubsection{Data}

The variables that I need to observe are the ones needed to construct the dependent and independent variables in the regression equations (34) to (37). The subscripts denote family $i$ in wave $t$, with father $f$ and mother $m$.

- Parental educational time inputs $\left(\tilde{q}_{i, f, t}, \tilde{q}_{i, m, t}\right)$

- Non-parental child care time inputs $\left(\tilde{n}_{i, t}\right)$

- Hourly wages $\left(\tilde{w}_{i, m, t}, \tilde{w}_{i, f, t}\right)$

- Hourly non-parental child care prices $\left(\tilde{p}_{i, t}\right)$

There are two data sources that I use to measure these variables: the ECLS-B, which is a panel dataset, and the American Time Use Survey (ATUS), which is a repeated cross-section sampled 
from the Current Population Survey (CPS).

The Early Childhood Longitudinal Study, Birth Cohort Data for hourly wages, hourly cost of child care, quality time from the parents in weekly frequency of activities, and non-parental child care time in hours per week come from the ECLS-B.

The ECLS-B reports incomes, the period of time over which the income was earned (a day, a week, two weeks, etc.), and the hours worked in a week. From these I can construct hourly wages for mothers and fathers, if they report these variables. If they did not report hours worked, I used part-time or full-time status to assign 30 or 40 hours worked per week, respectively. If they did not report earnings because they were out of the labor force (an issue confined mostly to mothers) I imputed their hourly wages using a regression of hourly wages on education, age, and age squared for the sample on which I could construct wages with reported income. I then evaluated this regression for observations where I could see education and age to get imputed hourly wages. Finally, to correct for taxes, I use the slopes (tax rates) from Table 2 of McGrattan and Prescott (2017). It is after-tax hourly income, not the directly reported pre-tax income, that I use in the estimation.

For the price of non-parental child care, I use weekly spending on each of the three main kinds of non-parental child care providers: relative, nonrelative, and center-based. Of these, I keep the primary source of non-parental child care. To calcuate cost per hour of non-parental child care, I use the total cost per time unit for the primary source of non-parental child care, and adjust it by the number of weeks that cost represents and the hours per week the child spends in that form of non-parental child care. After completing these steps, I have the price per hour of parental time and non-parental child care at the family level.

I define quality time as activities with the child that include talking and listening, singing, and reading to them. In the ECLS-B, these are reported as frequency per unit time. To convert these units into hours per week, I impute time per activity using the ATUS.

The American Time Use Survey Data on levels of time per activity for a parent with a given set of characteristics come from the ATUS. To impute levels of time per activity to the ECLS-B, I 
use a pooled sample from the ATUS from 2003 to 2016. This provides a time diary along with CPS variables on age, gender, marital status, labor force status, educational attainment, parental status, and child age. I restrict the sample to parents who are between 15 and 55, with a child 4 years or younger. I use information on gender, marital status (married/cohabiting or single), labor force status, and educational attainment, where educational attainment is discretized into those with less than a college degree or a college degree and higher. With this information, I group observations from the pooled sample by their characteristics along the aforementioned dimensions. For each group, I find survey-weighted averages of time spent on an activity for those who report engaging in it. The activities whose average duration I tabulate are time spent reading to the child and time spent talking with and listening to the child.

Imputation After linking parents in the ECLS-B with their appropriate group in the ATUS, I assign the level of time spent reading, and time spent talking and listening, to their respective activities in the ECLS-B; additionally, I assign the level of time spent talking and listening to the singing activity reported by parents in the ECLS-B. I do this because there is no singing activity reported in the ATUS. Once I have imputed time levels per activity associated with the ECLSB sample, I aggregate levels of quality time per parent in each family in each wave. This gives me quality time investments, non-parental time investments, after-tax hourly wages, and nonparental child care prices at the child-family pair and wave level. I pool cohabiting and married couples in the data and refer to them collectively as "married couples." Single mothers are defined as mothers in the sample who are a primary caregiver and who do not have a significant other living in the household with them. In addition, I select only families with observations in all three of waves 1,2, and 3. With this information, I can implement the estimation.

Estimating Sample Moments Moments from the estimation samples for couples and single mothers are presented in Table 2 and Table 3, respectively. I use wave 3 survey weights provided by the ECLS-B, which are designed to correct for attrition in the sample. 
Table 2: Married and Cohabiting Couples in the ECLS-B

\begin{tabular}{|c|c|c|}
\hline \multicolumn{3}{|l|}{ Waves 1-3 } \\
\hline Levels & & \\
\hline & mean & sd \\
\hline Education Time Father: Hours per Week & 5.55 & 2.94 \\
\hline Education Time Mother: Hours per Week & 7.99 & 2.74 \\
\hline Non-parental Care: Hours per Week & 30.47 & 13.94 \\
\hline Ratio of Time: Father/Mother & 0.76 & 0.50 \\
\hline Ratio of Time: Mother/Child Care & 0.41 & 0.50 \\
\hline Hourly Pay Mother, After Tax & 13.90 & 11.82 \\
\hline Hourly Pay Father, After Tax & 15.55 & 11.97 \\
\hline Hourly Price Child Care & 3.93 & 4.22 \\
\hline Ratio: Hourly Price Child Care/AT Hourly Wage Mother & 0.37 & 0.48 \\
\hline Age Resident Mother & 33.05 & 5.60 \\
\hline Age Resident Father & 34.94 & 6.09 \\
\hline Mother: BA or higher & 0.55 & \\
\hline Father: BA or higher & 0.47 & \\
\hline Marriage Rate & 0.92 & \\
\hline Below $100 \%$ Poverty Line & 0.01 & \\
\hline Below $185 \%$ Poverty Line & 0.08 & \\
\hline Observations & 3100 & \\
\hline
\end{tabular}

Note: Sample size is rounded to nearest 50, following National Center for Education Statistics (NCES) requirements.

Based on Table 2, the following qualitative points are apparent. First, fathers and mothers spend substantial time per week engaged in education time with their children. Within a couple, fathers invest on average $76 \%$ of the mother's time. This will be reflected in the complementarity estimates I find for father and mother time in my skill accumulation technology estimation. Next, I find that reported hours per week in non-parental child care are 30 on average, but there is a high variation in this level. The relative quantities of the two time inputs I measure in this sample, along with hourly prices for each, will translate into large estimated CES shares on non-parental child care. The ratio of mother time to non-parental child care is on average 0.41 , but with a high variation. Married or cohabiting mothers and fathers have hourly wages that are about four times higher than the hourly price of child care they use, although there is large variation in all of these prices within my sample. On average, the price of child care is $37 \%$ of the mother's hourly wage. Poverty in the sample of married or cohabiting parents is not common: only $1 \%$ are below the poverty line, while only $8 \%$ are below $185 \%$ of that threshold. Although I pool cohabiting and married couples in my estimation sample, most of these families are married couples: the marriage rate is $92 \%$. Both parents are on average in their 30 s, and the fraction in this group with a 
college degree or more is about half for each gender.

Table 3: Single Mothers in the ECLS-B

\begin{tabular}{|c|c|c|}
\hline \multicolumn{3}{|l|}{ Waves 1-3 } \\
\hline \multicolumn{3}{|l|}{ Levels } \\
\hline & mean & sd \\
\hline Education Time Mother: Hours per Week & 7.08 & 2.97 \\
\hline Non-parental Care: Hours per Week & 35.57 & 12.37 \\
\hline Ratio of Time: Mother/Child Care & 0.26 & 0.28 \\
\hline Hourly Pay Mother, After Tax & 9.13 & 10.78 \\
\hline Hourly Price Child Care & 2.41 & 2.77 \\
\hline Ratio: Hourly Price Child Care/AT Hourly Wage Mother & 0.32 & 0.40 \\
\hline Age Resident Mother & 28.07 & 6.36 \\
\hline Rates & & \\
\hline Mother: BA or higher & 0.14 & \\
\hline Below $100 \%$ Poverty Line & 0.22 & \\
\hline Below $185 \%$ Poverty Line & 0.42 & \\
\hline Observations & 1350 & \\
\hline
\end{tabular}

Note: Sample size is rounded to nearest 50 , following NCES requirements.

Table 3 presents a similar set of statistics for single mothers. Single mothers spend only slightly less time than married mothers in educational activities with their children, but non-parental child care time is on average five hours higher than for couples. The ratio of mother's time to nonparental child care time is correspondingly lower than for couples, at 0.26 (compared to 0.41 for the latter). Within a family, the ratio of mother time to non-parental child care time is almost half that of married or cohabiting families. The poverty rate of single mothers is twenty times higher than couples, at 22\%; for percent of single mothers below $185 \%$ of the poverty line is about five times higher, at $42 \%$. On average, single mothers make about five dollars per hour less than mothers parenting in couples. The ratio of this price to the mothers hourly wage is five percent smaller than for married and cohabiting mothers. Finally, the age of single mothers is on average 5 years lower than married or cohabiting mothers, and their educational attainment is one third that of married mothers: only $14 \%$ of single mothers have a college degree or more.

The comparisons across these two estimation samples help to establish priors about what the estimates of the skill accumulation technologies of each should look like. Because single mothers are the only source of parental time for their child, and the amount of non-parental time purchased is so large, one expects to see a larger CES share for non-parental child care in the single mother problem, ceteris paribus (I will expand more on that later in this section). 
From the estimation equations, one can see that the fixed effect correction adjusts for the logged parenting productivity $\theta_{f}$ or $\theta_{m}$ (the productivity of non-parental child care is normalized to 0 ). When I construct the predicted ratio of mother and non-parental child care time for couples in equation (36), I use fixed effects recovered from equations (35). When constructing investment for the estimation of the outermost aggregator in equation (37), I incorporate parental fixed effects recovered from (34) to (36).

For estimation weights, I used wave 3 weights-for the primary caregiver survey sample to estimate $\{\eta, \gamma\}$ and $\left\{\eta_{s}, \gamma_{s}\right\}$, and for the father survey sample to estimate $\rho$ and $\alpha$. Using a fixed effects estimator, a requirement for clustering standard errors is heterogeneity in treatment effects, which is not the case here (see Section 4 of Abadie, Athey, Imbens, and Wooldridge (2017)). However, because I impute hourly wages for parents who are not working using age and education, the wages of those observations may have errors that are correlated at the state level. This imputation is my motivation for clustering the standard errors at the level of state of residence.

\subsubsection{Estimation Results}

I estimate the mother/non-parental time aggregator separately for married and cohabiting mothers whose husbands also filled out a resident father questionnaire. In Table 4, this corresponds to models 1 and 2. Model 3 estimates the parameters governing how father and mother time combine, and model 4 reports estimates for the aggregator and investment and current skill. These are estimations of equations (34), (35), (36), and (37). Models 1, 2, and 3 use a fixed effects estimator, but model 4 uses an OLS estimator. This is because I cannot linearly separate the parenting productivities in that equation.

The nesting order I have chosen restricts the substitutability of father time with mother time or non-parental child care time to be the same. Alternative nestings would require that non-parental child care be equally substitutable with mother and father time, or that mother time be equally substitutable with father time and non-parental child care time. For couples, I chose the nesting that makes it most comparable with that of single mothers. I use this rule because there is not a clear ranking of alternative nestings by fit, and the parameter estimates for couples do not change

in a statistically significant way by changing this restriction with one exception (see the appendix 
for estimates with alternative nestings).

Table 4: Estimation Results: Skill Accumulation Technology

\begin{tabular}{|c|c|c|c|c|}
\hline & $\begin{array}{c}(1) \\
\text { Single } \\
\text { Mother }+ \\
\text { Child Care }\end{array}$ & $\begin{array}{c}\text { (2) } \\
\text { Cohabiting } \\
\text { Mother }+ \\
\text { Child Care }\end{array}$ & $\begin{array}{c}\text { (3) } \\
\text { Cohabiting } \\
\text { Father }+ \\
\text { Not Father }\end{array}$ & \begin{tabular}{c}
\multicolumn{1}{c}{$(4)$} \\
Outermost \\
Estimation
\end{tabular} \\
\hline $\log \left(\frac{\text { after-tax hourly wage mother }}{\text { cost per hour child care }}\right)$ & $\begin{array}{c}-0.308^{* * *} \\
(0.0856)\end{array}$ & $\begin{array}{c}-0.497^{* * *} \\
(0.0522)\end{array}$ & & \\
\hline $\log \left(\frac{\text { after-tax hourly wage father }}{\text { cost per hour child care }}\right)$ & & & $\begin{array}{c}-0.349^{* * *} \\
(0.0509)\end{array}$ & \\
\hline $\log ($ composite term $)$ & & & $\begin{array}{c}-0.599 * * \\
(0.199)\end{array}$ & \\
\hline $\log \left(\frac{\Lambda_{\text {type }, t}}{\Lambda_{\text {type }, t-1}}\right)$ & & & & $\begin{array}{l}0.545^{* * *} \\
(0.0298)\end{array}$ \\
\hline $\log \left(\frac{r_{t-1}}{r_{t}}\right)$ & & & & $\begin{array}{c}12.13^{* * *} \\
(0.674)\end{array}$ \\
\hline Constant & $\begin{array}{c}-1.117^{* * *} \\
(0.131) \\
\end{array}$ & $\begin{array}{c}-0.583^{* * *} \\
(0.0659) \\
\end{array}$ & $\begin{array}{c}-0.836^{* * *} \\
(0.0923) \\
\end{array}$ & $\begin{array}{l}0.770^{* * *} \\
(0.0417) \\
\end{array}$ \\
\hline $\begin{array}{l}R^{2} \\
\text { Observations }\end{array}$ & $\begin{array}{l}.1356 \\
1350\end{array}$ & $\begin{array}{l}.2039 \\
3100\end{array}$ & $\begin{array}{l}.15 \\
3100\end{array}$ & $\begin{array}{l}.5053 \\
2600\end{array}$ \\
\hline
\end{tabular}

Notes: Standard errors are in parentheses, clustered at the level of state of residence.

Sample sizes rounded to nearest 50, following NCES requirements. Sample sizes are pooled across waves 1 to 3 .

${ }^{*} p<0.05,{ }^{* *} p<0.01,{ }^{* * *} p<0.001$

These results yield the parameters in Table 5 for the skill accumulation technologies.

Table 5: Parameters of the Human Capital Accumulation Technology

\begin{tabular}{cccccccc}
$\rho$ & $\alpha$ & $\eta$ & $\gamma$ & $\eta_{s}$ & $\gamma_{s}$ & $\xi$ & $v$ \\
\hline-1.86 & 0.07 & -1.01 & 0.24 & -2.25 & 0.03 & -1.2 & 0.82 \\
$(0.42)$ & $(0.03)$ & $(0.21)$ & $(0.05)$ & $(0.90)$ & $(0.04)$ & $(0.14)$ & $(0.03)$
\end{tabular}

Note: Standard errors are in parentheses, clustered at the level of state of residence and calculated using the delta method.

Except for the single mother share $\gamma_{s}$, these parameter values are statistically different from zero at the $5 \%$ significance level. As for the single mother share, it has a p-value of 0.47 . The fact that $\gamma_{s}$ is small relative to $\gamma$ is consistent with my intuition based on sample summary statics.

When I translate the point estimates of $\eta, \eta_{s}$, and $\rho$ into elasticities of substitution, the estimation 
yields the values shown in Table 6.

Table 6: Elasticities of Substitution

\begin{tabular}{ccc}
$\begin{array}{c}\text { Father } \\
+ \text { Mother } \\
\frac{1}{1-\rho}\end{array}$ & $\begin{array}{c}\text { Married Mothers } \\
\text { + Non-parental } \\
\frac{1}{1-\eta}\end{array}$ & $\begin{array}{c}\text { Single Mothers } \\
\text { + Non-parental } \\
\frac{1}{1-\eta_{s}}\end{array}$ \\
\hline 0.35 & 0.50 & 0.31 \\
$(0.05)$ & $(0.05)$ & $(0.09)$
\end{tabular}

Note: Standard errors are in parentheses, clustered at the level of state of residence.

If the ratio of father over mother wage increases by $1 \%$, the ratio of father time to mother time invested in their child decreases by $0.35 \%$. If the denominator of both ratios changes to nonparental child care, the reaction to a $1 \%$ change in the former ratio is the same. For married mothers, a 1\% increase in the ratio of the mother's hourly wage to the price of non-parental child care decreases the ratio of her time to non-parental time invested in her child by $0.50 \%$. She is more responsive than married men or single mothers to the price of non-parental child care. Single mothers are the least responsive: they would adjust the ratio of their time to non-parental child care time by only $0.31 \%$. The share values, meanwhile, indicate that the level of her time would already be very low compared to the time inputs from couples raising children in this economy.

For intuition on the share parameters, consider a single mother whose hourly wage is exactly the same as the hourly price of non-parental child care care. Setting the prices equal to one another provides the clearest intuition for the role of the share parameter, and I chose to use the single mother technology because it has no outermost nesting like the married couple does around the ratio of prices of interest (which includes the price I subsidize in my analysis). The expression for the ratio of her quality time and non-parental child care time is:

$$
\frac{q}{n}=\left[\frac{1-\gamma_{s}}{\gamma_{s}} \frac{w \theta}{\left(1-\tau_{n}\right) p_{n}}\right]^{\frac{1}{\eta_{s}-1}}
$$

Imposing that the ratio of prices is 1 yields: 


$$
\frac{q}{n}=\left[\frac{1-\gamma_{s}}{\gamma_{s}}\right]^{\frac{1}{\eta_{s}-1}}
$$

Solving for $\gamma_{s}$, we have

$$
\gamma_{s}=\frac{1}{\left[\left(\frac{q}{n}\right)^{\eta_{s}-1}+1\right]}
$$

Knowing the elasticity of substitution between her time and non-parental child care, the share parameter pins down the ratio of her time and the time in non-parental child care she chooses. If these two levels are equal when the prices are the same, then the share parameters will be $\frac{1}{2}$; if the single mother's quality time inputs exceed the time she purchases in non-parental child care, even when the prices are the same, then the weight on her time will be greater than $\frac{1}{2}$, and vice versa. The degree to which the share parameter needs to adjust in order to explain the ratio of input choices when the price of each input is the same depends on the value of the complementarity parameter $\eta_{s}$. The more complementary the two inputs are, the more the share parameter will need to adjust to explain a large difference in their input levels.

\subsubsection{Discussion of Estimation Results}

There are three main takeaways from the skill technology estimation. First, the share parameters on father time and single mother time inputs are very low. Even if their hourly wages were the same as the prices of the other inputs in their technology, ratios of investment inputs would still show a relatively low level of inputs coming from their quality time. This is independent of the composition of hourly wages in either group. By contrast, non-parental child care has a large share in the investment technologies of both one- and two-parent families. If this share were zero, changes in the price of non-parental child care incurred by families (due to a subsidy such as the ones I examine) would have no effect on the price of investment or the skill accumulation of children.

The second takeaway concerns the relative elasticities of the three parental inputs with respect to non-parental child care. A $1 \%$ increase in the ratio of a single mother's hourly wage to the price 
of non-parental child care causes her to adjust the ratio of her time input to non-parental child care by $0.31 \%$. She does not heavily readjust her investment input choices because of the price change. Married mothers, by comparison, adjust their input choices more-by $0.50 \%$. A subsidy to non-parental child care will cause them to shift more heavily towards that input than for single mothers. Fathers parenting in a couple have an intermediate elasticity: they are more responsive to the ratio of input prices than single mothers, but less responsive than their wives. This matters for policy analysis in general equilibrium, such as the one I conduct, because it is informative about what one can expect parents in the economy to do with their time in the presence of a subsidy. All parents will shift inputs away from their own time and toward non-parental child care if the latter's price decreases. Ceteris paribus, this shift will not be dramatic; to achieve large changes in time use, the subsidy will have to be large. Time use is relevant because if parents easily substituted away from parenting and (at least partially) into time spent working, this would be a source of expansion in the tax base. My estimates indicate that expansions in the tax base from parents substituting away from parenting quality time and into labor should be expected to be small. Changes in the tax base will have to come instead from changes in the population distribution of skill rather than changes in parental time use.

The third and final takeaway is the role of investment in the outermost aggregator, which takes investment and the current stock of skill to produce tomorrow's skill. The share parameter on investment is high: its role in producing tomorrow's skill dominates the role of the current stock of skill. In addition, the complementarity parameter between investment and skill is $\xi=-1.2$, which means that they are more complementary than allowed in a Cobb-Douglas parameterization. The corresponding elasticity of substitution is 0.45 . Consider the multi-period estimation formulation presented above, and the intertemporal cost minimization equation that I use to derive my estimation equation for $\xi$. If the ratio of investment prices today and tomorrow changes by $1 \%$, this estimate says that the ratio of investments today and tomorrow will change by $0.45 \%$. The distribution of investments over time is not very sensitive to changes in the price of that investment across periods. In my model, unlike in the estimation data, there is a single period of childhood. In that context, there is no intertemporal cost minimization decision for parents. The interpretation of the complementarity parameter in a one-period technology is that it determines 
how quickly investment increases with the required adjustment to the current stock of skill. For example, if one wants to increase the current stock of skill by 10 percentage points, a skill accumulation technology that exhibits high complementarity (lower $\xi$ ) will require more investment than one with greater substitutability, for a given initial skill $\theta_{c}$ and share parameter $v$.

\subsubsection{Comparison with Other Findings}

There is a large body of work on the estimation of skill technologies (e.g., see Todd and Wolpin (2003) and Cunha and Heckman (2008) for a discussion of specification and estimation issues). Direct comparisons are problematic because specifications vary across studies, but are nevertheless qualitatively informative. The data requirements vary with the estimation equations; mine require information on time inputs and their prices. One widely cited estimation is due to Cunha, Heckman, and Schennach (2010). In that study, the authors use the NLSY79 Children and Young Adults suvey to estimate a CES skill accumulation technology for a two-dimensional skill vector containing both cognitive and non-cognitive skills. Each of these dimensions of skill is allowed to affect the evolution of the other dimension. This skill technology is very general; it nests several specifications examined in other studies. Cunha, Heckman, and Schennach (2010) find substitutability between investment and skill during early childhood. In that study, the authors are not specific about which inputs aggregate into investment in skill.

Lee and Seshadri (2018) estimate a skill technology with a single dimension of skill, but assume that there is no initial draw of skill (or rather, that it is identical for everyone and equal to 0 ). They thereby impose by assumption a property that Cunha, Heckman, and Schennach (2010) found as a result: that in the first period of life, initial investment and the initial stock of skill are substitutable. For other periods, however, Lee and Seshadri (2018) are unable to reject a CobbDouglas specification. This is a higher level of substitutability than what I find, but lower than that in Cunha, Heckman, and Schennach (2010). ${ }^{7}$

\footnotetext{
${ }^{7}$ In their 2016 working paper, Agostinelli and Wiswall (2016) the authors show that the assumptions made in Cunha, Heckman, and Schennach (2010) (specifically re-normalization of the latent skill variables) impose over-identifying restrictions which can bias the estimation of the complementarity parameter. The direction of the bias is explored in Monte Carlo simulations which demonstrate that the direction of the bias depends on several attributes of the estimation procedure. My estimation method does not re-normalize skill distributions in each period. This is because by using intertemporal cost minimization to derive estimation equation (37), I am able to avoid using measures of skill in the estimation of the skill accumulation technology.
} 
My estimates show complementarity between investments and skill early in life. I do not ignore heterogeneity in the first measure I have of skill at 9 months, as in the specification of Lee and Seshadri (2018), because it doesn't appear to be noise in my data and because I have no observations of the investment that generated that initial stock (motivating regressions for these two claims are in the appendix). If the investment were solely responsible for the skill I observe at 9 months, the skill would already be correlated with family income. That is not what I find. See the appendix of Cunha, Heckman, and Schennach (2010) for a discussion of the implications of substitutability versus complementarity between skill and investment for policy design.

In my framework, children being raised in families with low income are more likely to be children of single mothers, who use a different technology than couples to invest in their children. This technology emphasizes non-parental child care more than the one couples use: the share on parental time is much lower. However, the ability of parents to adjust their own time use in response to a change in child care prices is higher for couples than for single mothers. On net, the larger share parameter dominates, so that subsidies targeted to single mothers target the families whose costs of investment are most sensitive to the price of non-parental child care. This heterogeneity across family structures is uncovered with my specification choice, unlike those used in other studies.

\subsection{Other Externally Estimated Parameters}

In Table 7, the level of lump-sum transfers $T$, the level of child support payments $T_{c s}$, and the price of $p_{n}$ are set to $8 \%$ of output, $28 \%$ of the average per-family transfer, and $35 \%$ of the average mother's wage, respectively. The first target is from the ratio of government transfers to persons for federal benefits from social insurance funds, Supplemental Nutrition Assistance Program (SNAP), supplemental security income, refundable tax credits, and other (which includes payments to nonprofit instutitions and student loans, among other categories) to GDP from the National Income and Production Accounts (NIPA) tabulations.The second is the ratio of average child support payments per month per capita to average monthly government transfers per family. The third is the average ratio of hourly price of non-parental child care to hourly wages of mothers in the ECLS-B. See the appendix for further details on the estimation of these parameters. 
Table 7: Externally Estimated Parameters

\begin{tabular}{lccc} 
Symbol & Name & Source & Value \\
\hline$T$ & Transfers & NIPA & $8 \%$ of output \\
$T_{c s}$ & Child Support & Census and NIPA & $28 \%$ of $T$ \\
$\kappa$ & $p_{n}$ coefficient & ECLS-B & $35 \%$ ave. mother's wage
\end{tabular}

\subsection{Internally Calibrated Parameters}

The parameters $b, \psi_{s}, \psi_{m c}, \lambda$ are chosen to bring the model moments in the baseline as close as possible to the moments in the "Data" column of Table 8. The coefficient $b$ controls the degree of altruism; $\psi_{s}, \psi_{m c}$ are the marginal utilities of leisure for singles and married couples, respectively. The parameter $\lambda$ is a shifter in the skill technology that scales up investment into efficiency units in the production of skill.

The moments I chose these parameters to match in the model compared with the data are the correlation of child skill with family income, the average labor supply of parents with children under 5 who are between 20 and 80 years old, the percent of single mothers raising children under 5 , and the average time invested by parents of each family structure type. Note that the correlation of child skill and family income grows to 0.33 by the time the child is 5 years old (ECLS-B). By contrast, when children are 9 months old, the measures of skill available in the data are uncorrelated with family income, although they do have predictive power for later child test scores at age 4 . For regressions supporting these points, see the appendix.

There are two internal calibration moments for which it has proven difficult to match the model with the data: the correlation of child skill and family income and the levels of time investments. For the former, in this model the family incomes of couples and singles are quite different because the marriage market outcome is so closely related to skill. This means that the income distribution for families raising young children looks like two slightly overlapping distributions, one for single mothers and one for couples. Within each group the correlation of child skill and family income is lower than the statistic reported in Table 8; once the differences across family structures are accounted for the correlation looks much higher (compared to the correlation within family structures) because of the difference in income levels across the two structures is so high. For the 
latter, the levels of time investments are wrong in the sense that the magnitudes are off, but they are also in the wrong order: in the data, single mothers more education time, on average, than married fathers. In my model there is no gender wage gap, and the model lacks one reason why fathers in the data have a higher opportunity cost of their time than mothers do. Consequently, fathers in the model oversupply parenting time relative to single mothers.

Table 8: Internal Calibration: Targeted Moments + Parameters

\begin{tabular}{lccc}
\multicolumn{1}{c}{ Moment } & Source & Data & Model \\
\hline Corr(child skill, family income) & ECLS-B & 0.33 & 0.39 \\
Average labor supply & CPS & 0.31 & 0.30 \\
Percentage single mothers & ECLS-B & 0.20 & 0.20 \\
Average time investments & ECLS-B (MM,MF,SM) & $(8,5.6,7)$ & $(9.2,7.6,4.8)$
\end{tabular}

Notes: Internal calibration targeted moments (data v. model).

Time investments are in units of hours per week.

\begin{tabular}{lcc} 
Parameter & Name & Value \\
\hline$b$ & Altruism coefficient & $0.29 \times \beta$ \\
$\left\{\psi_{s}, \psi_{m c}\right\}$ & Marginal utility of leisure & $\{1.4,1.4\}$ \\
$\lambda$ & Productivity of investment & 45 \\
& &
\end{tabular}

Notes: Parameter names and values for internal calibration.

\subsection{Untargeted Moments}

In Table 9, I compare the implications of this model with six untargeted moments: the correlation of hourly wages in spouse (or cohabiting partners), the correlation of parental time inputs within a couple, the ratio of average hourly wages in married or cohabiting mothers with single mothers, the average ratio of mother and father time, the average ratio of mother time and non-parental child care time, and the marriage rate of the poor. For a comparison of the income distribution in the model with the data, see the appendix.

Table 9 shows that the random search marriage market I model captures an appropriate degree of assortative matching among spouses: the correlation of wages within couples is a close fit with the data. However, within a couple the model implies a higher correlation of time inputs than seen in the data. This partly reflects the fact that the levels of wages for men and women in the model 
economy have identical distributions, but in the data there is an unmodelled gender wage gap.

Table 9: Untargeted Moments (Model Fit)

\begin{tabular}{lccc}
\multicolumn{1}{c}{ Moment } & Source & Data & Model \\
\hline Correlation of wages within a couple & ECLS-B & 0.28 & 0.29 \\
$\begin{array}{l}\text { Correlation of time inputs within a couple } \\
\begin{array}{l}\text { ave. hourly wages, single mothers } \\
\text { ave. hourly wages, mc mothers }\end{array}\end{array}$ & ECLS-B & 0.33 & 0.46 \\
Average $\frac{\text { father time }}{\text { mother time }}$ & ECLS-B & 0.67 & 0.86 \\
Average $\frac{\text { mother time }}{\text { non-parental child care time }}$ & ECLS-B & 0.77 & 0.81 \\
Marriage rate of the poor & ECLS-B & 0.37 & 0.18 \\
& ECLS-B (wave 3) & $52 \%$ & $6.4 \%$
\end{tabular}

Notes: Table 9 shows relevant moments for the implications of the model for sorting across family structures, assortative matching in marriage, patterns of time inputs for investments in child skill and the marital status composition of the poor. For the last moment, the poor in the model are defined as the bottom $20 \%$ of the pre-tax family income distribution corrected with CE scales. This follows the definition of poor families used in the policy exercise of the next section. Correlations are Pearson correlation coefficients, weighted with survey weights in the ECLS-B and using the analogous distribution in the model. Ratios use empirical moments from Tables 4 and 5 and analogous moments using the baseline equilibrium of the model.

To examine how mothers sort into the family structures, the third moment looks at the ratio of their wages across family structures. In the data, single mothers have lower hourly wages than married mothers. I assume that hourly wages are correlated with parenting productivity in my estimation, so the sorting across family structures has implications for the parenting productivities using each of the two technologies in the population. My model endogenously captures the qualitative attribute of the data: mothers with higher skill tend to parent in a couple. However, the average hourly wages of single and married mothers in the model are closer together than in the data. More higher-wage women parent as single mothers in the model than in the data.

The next two moments in Table 9 show the average ratios of time inputs in the model and in the data. The ratio of time inputs within a couple is quite close to the data, but the ratio of mother time with non-parental child care time is too low in the model. This reflects the fact that I did not model child care quality choice, so that only the intensive margin of non-parental child care time can adjust to increase child care's contribution to investment. 
Finally, the last row of Table 9 shows the marriage rate of the poor in the model compared with the data. The poor in the model are defined as the bottom $20 \%$ of the pre-tax family income distribution corrected with CE scales. This follows the definition of poor families used in the policy exercise of the next section. The close link between skill and marriage in this model means that poor parents (low earners) raising young children are rarely married.

\section{Policy Experiment and Results}

I vary $\tau_{n}$ over the interval $[0,1]$ with three eligibility rules: universal, poverty-tested, and familytested. Under a universal eligibility rule, every parent receives the subsidy, whereas under a poverty-tested rule only families in the bottom $20 \%$ of the CE-adjusted income distribution for parenting families in the baseline economy receive the subsidy. I chose this approach so that the mass of those eligible for the poverty-tested and single mother subsidy is the same in the baseline (20 percent of parenting families), which makes the two eligibility criteria more comparable. As Table 9 documents, in practice this means that in the baseline economy single mothers are overrepresented in the poor compared with the data. For each $\tau_{n}$ value I solve for equilibrium and record household decisions for every possible family type, as well as the endogenous population weights assigned to that family type.

A family type is the marriage structure (single mother, single father, or married couple), the productivity type of the parent(s), and the initial skill of the children (every single mother and married couple raises one boy and one girl). An equilibrium output in the model is structured like a survey dataset, with observations at the family type level and the endogenous population weights being analogous to survey weights. I use this information to compute welfare changes under different policies. For each eligibility criteria, I find the subsidy level that implements the largest ex ante welfare gain for children at birth. I compare these maximized welfare gains, looking at the distribution of these gains in the population after birth as well as across initial skill types of children before they know the family they will be raised in.

For the welfare criterion used to select the best eligibility rule, using either the baseline or the subsidized equilibrium distribution of families gives the same ranking. For decompositions of welfare 
changes, I use the distribution of families in the baseline equilibrium, and when I present changes in aggregates I use the distribution of families in the subsidized equilibrium. The former choice is to reflect how the distribution of families in the baseline (those a policymaker is answerable to when implementing these policies) will evaluate the proposed child care subsidy. The latter choice is to reflect how the subsidy's affect on individual choices in turn distorts aggregates in the subsidized equilibrium.

The rest of this section proceeds as follows. First, I report the formulas I use to calculate welfare gains for different levels and eligibility rules of the non-parental child care subsidy. Second, I report the best attainable outcome for each eligibility rule (universal, subsidies to the poor, and subsidies to single mothers), using ex ante welfare by child initial skill and decompositions of welfare gains by attributes of the population such as age, gender, marital status, and adult skill level. Differences between the effects of the three eligibility rules are apparent with the decompositions I report and analyze in the last subsection of these results. Third, I discuss how some features of my model specificaton are related to the results.

\section{Welfare Measures}

The equation to compute welfare gains for each type is:

$$
\Delta W_{j}^{\text {type }}\left(z ; \vec{\theta} \mid \tau_{n}\right)=\exp \left(\frac{V_{j}^{\text {type }}\left(z ; \vec{\theta} \mid \tau_{n}\right)-V_{j}^{\text {type }}\left(z ; \vec{\theta} \mid \tau_{n}=0\right)}{\sum_{\text {age=j }}^{3}\left(\beta^{\text {age }-j}\right)}\right)
$$

where type $\in\{S M, S F, M C\}$ is the family structure type, $z$ is the state space at that phase of life for that family type, and $\vec{\theta}$ is the vector of adult skill types, equal to $\theta$ in the case of single parents or $\theta_{f}, \theta_{m}$ in the case of married couples. The state space $z$ contains the asset stock; equation (38) uses the policy choice for that household at that age, in the previous period. The object

$\Delta W_{j}^{\text {type }}\left(z ; \vec{\theta} \mid \tau_{n}\right)$ is the consumption-equivalent change in lifetime utility evaluated at age $j$, for a given family structure and composition. To aggregate these welfare changes, I use the distribution of families in the subsidized or baseline equilibrium (I am specific in each case). I construct the distribution of families I use to aggregate welfare using the appropriate joint distribution $\mu$, marriage decision rules, and the exogenous distribution from which the initial skill of the child is 
drawn.

Ex ante welfare changes in consumption-equivalent units are computed as follows:

$$
\Delta W_{0}\left(\theta, g \mid \tau_{n}\right)=\mathbb{E}_{\text {type }, \vec{\theta}, \theta_{c}}\left[\Delta W_{1}^{\text {type }}\left(z ; \vec{\theta} \mid \tau_{n}\right) \mid \theta, g\right]
$$

This is the consumption-equivalent change in ex ante lifetime utility, evaluated at the skill type $\theta$ and gender $g$ of the child, at an equilibrium indexed by the subsidy $\tau_{n}$. Taking the expectation of $\Delta W_{1}^{\text {type }}$, as defined in equation (38), over family structure type, the vector of skills for the adults in

the family $\vec{\theta}$, and the initial skill of the child $\theta_{c}$, requires the endogenous distribution of skill for the first two and the exogenous distribution of initial skill for $\theta_{c}$. For the endogenous distribution of skill, one can use either the baseline or the subsidized equilibrium's distribution to calculate ex ante welfare gains. Accordingly, I indicate in each result whether I use the distribution of families in the subsidized equilibrium or in the baseline equilibrium.

\subsection{Welfare Gains: Overall and Decomposition}

I tabulate gains in welfare ex ante (for the unborn), and ex post (by age, skill, marital status, and gender groups). When describing and analyzing the distribution of welfare gains in the economy under different subsidies, I have separated adults into two groups: low and high skill. Low skill is defined as those below the 20th percentile of hourly wages in the baseline equilibrium. This procedure allows for more heterogeneity in the high-skilled group than the low-skilled group, but a finer decomposition does not reveal a qualitatively different result from the one I discuss below.

\subsubsection{Ex Ante Welfare Gains}

Table 10 reports ex ante welfare gains for children, overall and by initial skill group (low, medium, and high). In addition, the second column reports the subsidy level and the third column reports the marriage rate at that equilibrium. All welfare gains reported in the last four columns are in consumption-equivalent units, with expectations taken over the endogenous distribution of families in the subsidized equilibrium and the exogenous distribution of initial skill.

Overall, universal subsidies yield welfare gains that are 3.5 percentage points higher than sub- 
sidies to single mothers, and 3.9 percentage points higher than subsidies to poor families. The subsidy levels that achieve maximal gains under the different elibility rules are lowest for universal subsidies at 70\%; for the two targeted policies I consider, they are $85 \%$. Marriage rates rise under a universal subsidy and decrease under the two targeted subsidies; by making child care cheaper for any potential match, the subsidy lowers the threshold strategy of the marriage decision rule. By comparison, targeted child care subsidies raise the value of being a single parent by more. The reason it does so for the single mother subsidy is clear; for subsidies to the poor, it is harder to qualify for the subsidy as a couple than as a single mother (see Table 9 for a comparison of the composition of the poor in the model and in the ECLS-B).

Table 10: Ex Ante Welfare Gains, Subsidized Family Distribution

\begin{tabular}{lcccccc} 
& & & & Welfare Gain & \multicolumn{3}{c}{ Welfare Gain by Skill } \\
Eligibility & $\tau_{n}^{*}$ & Marriage rate & Average & Low & Medium & High \\
\hline Universal & $70 \%$ & $100 \%$ & 5.9 & 6.4 & 5.8 & 5.6 \\
Single Mothers & $85 \%$ & $76 \%$ & 2.4 & 3.6 & 2.2 & 1.5 \\
Poor Families & $85 \%$ & $74 \%$ & 2.0 & 3.5 & 1.8 & 1.0 \\
\hline
\end{tabular}

Notes: Table 10 reports, by eligibility rule, the welfare-maximizing subsidy level, the marriage rate, and welfare gains on average and by initial skill of the child. Welfare gains are computed using expected gains over outcomes, using the distribution of families in the subsidized equilibrium, and are reported in percent gain of consumption-equivalent units that are rounded to the nearest tenth of one percent. Universal subsidies yield the highest gains, followed by single mother subsidies and subsidies to the poor. Gains are decreasing in initial skill.

In Table 11, I present welfare gains using the distribution of families at the baseline equilibrium. This is a relevant set of statistics because, conceivably, these are the families to whom policy makers are answerable when the policy is implemented. By comparing Table 10 with Table 11, it is evident that the ranking remains the same, with the level of gains almost identical. This is despite large change in economic aggregates and the distribution of families due the subsidies, as discussed in Tables 12 and 13. 
Table 11: Ex Ante Welfare Gains, Baseline Family Distribution

\begin{tabular}{lccccc} 
& & Welfare Gain & \multicolumn{3}{c}{ Welfare Gain by Skill } \\
Eligibility & $\tau_{n}^{*}$ & Average & Low & Medium & High \\
\hline Universal & $70 \%$ & 5.9 & 6.4 & 5.9 & 5.5 \\
Single Mothers & $85 \%$ & 2.1 & 3.3 & 1.9 & 1.4 \\
Poor Families & $85 \%$ & 1.8 & 3.1 & 1.5 & 1.0
\end{tabular}

Notes: Table 11 reports, by eligibility rule, the welfare-maximizing subsidy level and welfare gains on average and by initial skill of the child. Welfare gains are computed as expected welfare gains over outcomes, using the distribution of families in the baseline equilibrium, and are reported in percent gain of consumption-equivalent units that are rounded to the nearest tenth of one percent. The ranking of subsidies is the same as in Table 10; also as in Table 10, gains are decreasing in initial skill.

\subsubsection{Aggregate Moments: Comparison Across Eligibility Rules}

Table 12 contains aggregate moments and equilibrium objects under the three eligibility rules at the welfare-maximizing level of $\tau_{n}$. These aggregates are informative about the sources of welfare gains reported in Table 10 and Table 11. Under the single mother or universal subsidy, the labor income tax falls relative to the baseline by 1.8 and 0.2 percent, respectively. By comparison, a subsidy to the poor requires a 0.8 percent increase in labor income tax. Subsidies to the poor disincentivize skill investment, and so dampen the expansion in the labor income tax base compared to the other two eligibility rules (the percent change in $H$ is lowest for subsidies to the poor). The price of non-parental care reflects changes in the average hourly wage under each eligibility rule: it rises the most under the universal subsidy (a 12 percent increase) and the least under the subsidy targeted to the poor (a 5.7 percent increase). This reflects the magnitude of the change in the average wage, which follows the same ranking as the change in $p_{n}$. 
Table 12: Macroeconomic Moments and Equilibrium Objects Across Eligibility Rules

\begin{tabular}{lccccccccccc} 
& $r$ & $\tau_{y}$ & $p_{n}$ & $Y$ & $C$ & $H$ & $K$ & $L$ & $N$ & $Q_{f}$ & $Q_{m}$ \\
\hline Universal & 0.999 & 0.998 & 1.120 & 1.249 & 1.240 & 1.245 & 1.257 & 0.994 & 1.893 & 1.132 & 1.029 \\
Single Mothers & 1.000 & 0.982 & 1.079 & 1.055 & 1.054 & 1.053 & 1.059 & 1.001 & 1.095 & 0.894 & 0.927 \\
Poor Families & 0.999 & 1.008 & 1.057 & 1.023 & 1.023 & 1.019 & 1.031 & 1.003 & 1.108 & 0.855 & 0.873
\end{tabular}

Notes: Table 12 reports macroeconomic moments and equilibrium objects across eligibility rules at the welfaremaximizing level of $\tau_{n}$. Moments are reported as fractions of the baseline level, to facilitate interpretation in units of percentage change, and are rounded to the third decimal place (nearest tenth of a percent change). Recall, from the Model section, that the price of non-parental care is not an aggregate endogenous state but simply a function of it in this model. Moving from left to right, the columns report the interest rate, the price of child care (pre-subsidy), aggregate output, consumption, labor efficiency units supplied, capital stock, leisure, non-parental care time, quality time from fathers, and quality time from mothers. All aggregates use the distribution over families in the subsidized equilibrium.

Output, consumption, hours, the capital stock, child care use, and parental time investments (columns 5 to 8 and 10 to 12 of Table 12) increase the most under the universal subsidy. By contrast, leisure decreases under the universal subsidy, and average parental time investment levels decrease under the targeted subsidies. The increase in the labor income tax rate under povertytested subsidies is necessary because the expansion in the supply of labor efficiency units is low, while the increase in demand for child care is high enough that the costs of running the child care subsidy program offset the gains resulting from expansions in the labor income tax base.

Note that the estimated CES complementarity between parental time and non-parental time in the production of child skill means that, for a fixed level of parenting productivity, a change in the ratio of prices does not get completely reflected as a change in the ratio of inputs: that is, parenting time will not be completely crowded out by non-parental care as the subsidy increases. However, as the distribution of skill in the population increases, the opportunity cost of parenting time also goes up, while the productivity of non-parental time remains fixed. The ratio of time inputs into child skill development will reflect the increased value of parental time, as well as the lowered price of non-parental child care. Note that inputs from parents only increase under a universal subsidy. Parental time investments increase under the universal subsidy, but not under the targeted subsidies, because the marriage rate increases in the former and not the latter. Married couples in turn use a technology that requires higher levels of parental time inputs. Inputs from fathers fall in the two targeted subsidies due to decreases in the marriage rate, while inputs from 
mothers fall both because of lower marriage rates and because the composition of inputs adjusts to the subsidy on child care. Although the latter force still applies under universal subsidies, the higher marriage rate that results under that eligibility rule means that more mothers are parenting in a couple, and married mothers contribute more hours than single mothers do (see Table 8 in the Estimation section).

Table 13: Income and Earnings Levels and Gini Coefficient Across Eligibility Rules

\begin{tabular}{lcccccccc} 
& \multicolumn{2}{c}{ Income } & \multicolumn{2}{c}{ Earnings } & \multicolumn{2}{c}{ Pre-tax } & Income & \multicolumn{2}{c}{ Pre-tax Earnings } \\
& mean & Gini & mean & Gini & mean & Gini & mean & Gini \\
\hline Universal & 1.235 & 0.493 & 1.248 & 0.823 & 1.236 & 0.436 & 1.247 & 0.823 \\
Single Mothers & 1.054 & 1.123 & 1.056 & 1.040 & 1.052 & 1.142 & 1.054 & 1.040 \\
Poor Families & 1.023 & 1.186 & 1.020 & 1.063 & 1.023 & 1.212 & 1.021 & 1.063 \\
\hline
\end{tabular}

Notes: Table 13 reports average income and earnings, both before and after tax, as well as the Gini coefficient for each measure. Moments are reported as fractions of the baseline level, to facilitate interpretation in units of percentage change, and are rounded to the third decimal place (nearest tenth of a percent change). Before normalizing, averages are calculated using the distribution over families in the subsidized equilibrium. Income and earnings are reported after labor income taxes are applied. Income is the sum of labor earnings, income from wealth, and lump-sum transfers, net of labor income taxes. Pre-tax income contains lump-sum transfers. Relative to the baseline, both income and earnings increase the most under the universal subsidy. Inequality as measured by the Gini coefficient decreases under the universal subsidy and increases under the other two eligibility rules.

Table 13 describes the behavior of the earnings and family income distributions relative to the baseline under the three eligibility rules. Universal subsidies increase average earnings and income the most, and they do so while decreasing inequality. For the two targeted subsidies, however, inequality increases even as levels of earnings and income increase. Targeted subsidies increase inequality by increasing the number of single parents, who have lower family incomes, and by distorting the skill investment decision at the eligiblity threshold in the case of subsidies to the poor. Note that after-tax gains in earnings and income under subsidies targeted to single mothers are higher than pretax levels, while for subsidies to the poor the opposite is true, reflecting different equilibrium changes in labor income taxes under the two eligibility rules. Note also that, by comparing the Gini coefficients of before- and after-tax income, one can see that the labor income tax acts to decrease dispersion. The dispersion of earnings is unaffected because the labor income tax is linear. 


\subsubsection{Decomposition of Welfare Gains}

Table 14 decomposes welfare gains by marital status and age across eligibility rules at the welfaremaximizing level of $\tau_{n}$. Besides benefiting directly from receiving the subsidy, gains during parenthood occur due to altruistic enjoyment of insurance to marriage market risk, even for ineligible parents, and because of any decrease in the labor income tax resulting from the subsidy. Later in life, families that were able to save more during parenthood because of lower parenting costs can afford to finance more consumption and so see higher gains. Single fathers experience much lower gains from this particular source, and this is reflected in concentration of welfare gains for that group during the parenting phase.

Table 14: Welfare Gains by Age and Marital Status

Universal Subsidy

Average Married Couples Single Fathers Single Mothers

\begin{tabular}{|c|c|c|c|c|}
\hline $\begin{array}{l}\text { Parenthood } \\
\text { Worker } \\
\text { Old }\end{array}$ & $\begin{array}{l}5.7 \\
1.6 \\
1.4\end{array}$ & $\begin{array}{l}5.7 \\
1.6 \\
1.4\end{array}$ & $\begin{array}{r}3.9 \\
0.0 \\
-0.1\end{array}$ & $\begin{array}{l}7.6 \\
1.7 \\
1.8\end{array}$ \\
\hline \multicolumn{5}{|c|}{ Targeted: Single Mothers } \\
\hline $\begin{array}{l}\text { Parenthood } \\
\text { Worker } \\
\text { Old }\end{array}$ & $\begin{array}{l}2.2 \\
0.6 \\
0.5\end{array}$ & $\begin{array}{l}1.2 \\
0.4 \\
0.2\end{array}$ & $\begin{array}{l}1.9 \\
0.1 \\
0.0\end{array}$ & $\begin{array}{l}8.4 \\
2.5 \\
2.6\end{array}$ \\
\hline \multicolumn{4}{|c|}{ Targeted: Poor Families } & Single Mothers \\
\hline $\begin{array}{l}\text { Parenthood } \\
\text { Worker } \\
\text { Old }\end{array}$ & $\begin{array}{l}2.0 \\
0.3 \\
0.2\end{array}$ & $\begin{array}{l}1.2 \\
0.3 \\
0.3\end{array}$ & $\begin{array}{l}1.5 \\
-0.1 \\
-0.1\end{array}$ & $\begin{array}{l}6.8 \\
0.4 \\
0.3\end{array}$ \\
\hline
\end{tabular}

Notes: Table 14 shows the welfare gains for each eligibility rule at the optimal subsidy level for that rule. Gains are reported at each age, overall and by family structures. Welfare gains are in percentage point gains of consumption equivalent units, and are aggregated using the distribution of families at the subsidized equilibrium. Gains are rounded to the first decimal point (nearest tenth of a percent gain). Under all three eligibility rules, single mothers gain the most at all phases of life compared to single fathers and married couples. Because subsidies to the poor require a slight increase in the labor income tax rate and result in the lowest increase in earnings (see Table 12), gains are lowest for this eligibility rule.

Single mothers benefit more than married couples under all three eligibility rules I consider. This 
is because a given level of subsidy has a larger effect on their price of investment compared with couples (due to the point estimates of the skill accumulation technology, which I present and discuss in the Estimation section). Compounding this, under either of the targeted subsidies single mothers are far more likely to receive the subsidies than couples. Couples under the two targeted subsidy regimes benefit altruistically from marriage market insurance to their children, and directly from any equilibrium decrease in the labor income tax.

Table 15: Welfare Gains by Marital Status, Gender, Age and Skill

\begin{tabular}{llllllll} 
& \multicolumn{9}{c}{ Universal Subsidy } & \multicolumn{2}{c}{ Suble } \\
& Married Couples & \multicolumn{2}{c}{ Single Fathers } & \multicolumn{2}{c}{ Single Mothers } \\
& Low & High & Low & High & Low & High \\
\hline Parenthood & 6.0 & 5.7 & 3.9 & 3.9 & 7.8 & 7.5 \\
Worker & 1.5 & 1.6 & 0.0 & 0.0 & 1.5 & 1.7 \\
Old & 1.4 & 1.4 & -0.1 & -0.1 & 1.6 & 1.9 \\
& & & & & & \\
\hline
\end{tabular}

\begin{tabular}{|c|c|c|c|c|c|c|}
\hline & \multicolumn{4}{|c|}{ Targeted: Single Mothers } & \multirow{2}{*}{\multicolumn{2}{|c|}{ Single Mothers }} \\
\hline & \multicolumn{2}{|c|}{ Married Couples } & \multicolumn{2}{|c|}{ Single Fathers } & & \\
\hline & Low & High & Low & High & Low & High \\
\hline Parenthood & 1.3 & 1.2 & 1.9 & 1.9 & 8.5 & 8.1 \\
\hline Worker & 0.5 & 0.4 & 0.1 & 0.1 & 2.1 & 3.8 \\
\hline \multirow[t]{4}{*}{ Old } & 0.4 & 0.2 & 0.0 & 0.0 & 2.3 & 3.9 \\
\hline & \multicolumn{4}{|c|}{ Targeted: Poor Families } & \multirow{2}{*}{\multicolumn{2}{|c|}{ Single Mothers }} \\
\hline & Marr & Couples & Singl & Fathers & & \\
\hline & Low & High & Low & High & Low & High \\
\hline Parenthood & 2.0 & 0.8 & 1.6 & 1.6 & 8.2 & 0.8 \\
\hline Worker & 0.6 & 0.2 & -0.1 & -0.1 & 0.3 & 0.3 \\
\hline Old & 0.6 & 0.1 & -0.1 & -0.1 & 0.3 & 0.3 \\
\hline
\end{tabular}

Notes: Table 15 shows the welfare gains for each eligibility rule at the optimal subsidy level for that rule. Gains are reported at each age, overall and by family structures. Welfare gains are in percentage point gains of consumption equivalent units, and are aggregated using the distribution of families at the subsidized equilibrium. Gains are rounded to the first decimal point (nearest tenth of a percent gain). Across eligibility rules, all parents benefit, even the ineligible: this is due to decreases in the labor income tax under universal and single-mother subsidies, as well as the marriage market insurance the subsidy provides under all three eligibility rules (which parents internalize due to altruism). The gains in the single father column appear identical because of rounding.

Table 15 provies the finest decomposition of welfare gains that I analyze. Here, low skill is the bottom 20 percent of the skill distribution in the economy. Under all three subsidies, all parents benefit, but single fathers of any skill level see welfare losses later in life. As with ex ante welfare 
gains, welfare gains for adults at any phase of life are decreasing in skill.

Overall, subsidy levels that maximize ex ante welfare for a given eligibility rule are higher under targeted subsidies than under the universal subsidy. The optimal level of the subsidy is determined by balancing gains from insurance and increases in skill with the cost burden of funding the program. With targeted subsidies, the costs are lower and it takes higher levels of the subsidy for these costs to begin to offset gains from insurance and increases in skill. Insurance is an important source of welfare gains here because everyone in this economy faces risks over their own initial skill, the initial skill of their child, and the skill of their potential spouse. Without intervention, skill investment is the only way to insure against those risks. Welfare gains continue to increase with the subsidy until it is quite high (especially under the targeted eligibility rules) because it provides insurance against poor outcomes, which in this environment can happen to anyone.

\subsection{Model Specification: Effects on Welfare Gains}

Welfare gains from the subsidy schemes that I study are fairly large, on the order of $2 \%$ to $6 \%$ (Tables 10 and 11). These are comparable the existing literature on the welfare gains from subsidizing skill accumulation in early childhood, or even later in life (Daruich (2017), Abbott, Gallipolli, Meghir, and Violante (2018)). As discussed in the Model section, a child care subsidy in this environment yields welfare gains from four main sources: it insures against a low initial skill for the child, against being born into a family with fewer resources, and against a poor outcome in a frictional marriage market. In addition, it partially addresses a fiscal externality to parental investments in their child's skill. ${ }^{8}$

Because I have found that my data do not allow me to predict the initial skill of the child using family attributes, in the model I have not made the distribution from which the initial child skill is drawn depend on parental attributes. This choice magnifies the degree of risk a child faces once they know their initial skill but are still uncertain about their family: if skill were very persistent across generations, knowing your initial skill would be very informative about the sort of parents

\footnotetext{
${ }^{8}$ The term "fiscal externality" is viewed as a misnomer by some economists. Here I use it in the sense that a child care subsidy affects those not receiving the subsidy (those not parenting, or parents who are not eligible) indirectly by allowing for a decrease in the labor income tax in equilibrium. See Buchanan (1966) and Browning (1999).
} 
you would have. Likewise, if initial skill were drawn from a distribution that was endogenous, gains from insuring this risk would be realized by directly affecting that distribution. Consequently, the welfare gains from universal subsidies to children before they know their initial skill or family are quite large in magnitude: these are unavoidable and important shocks to lifetime utility.

In addition, because I have found that I cannot predict initial skill with the measures of prenatal investment that I have in the ECLS-B, I have not modelled choices of parents that can affect the initial skill of the child (see the appendix for regressions motivating this and other modelling choices). ${ }^{9}$ In addition to the fact that initial skill is not persistent across generations, this means that all parents face the same risk over the initial skill of their children: they differ in their ability to compensate for a low initial skill by investing more. A model with persistence in initial skill would reduce this source of risk and open up other policy discussions (see Abbott, Gallipolli, Meghir, and Violante (2018), and Rustichini, Iacono, and McGue (2016)).

Risk from the marriage market arises from several sources. The marriage market that I model is a simple one: potential spouses are matched randomly, and positive assortative matching by skill occurs because adults have the power to reject the spouse they match with. A marriage market where search was more directed would reduce the risk faced by a new adult over the potential spouse they meet, by giving them some control over it. Here, I only allow parents to provide insurance against marriage market risk by ensuring that their child has enough skill to not be rejected by the spouse they meet. The individual cannot affect her chances, but must appear on the marriage market with the skill she has as an adult and make her decision. I interpret the risk added by the presence of the marriage market as an upper bound: with a directed search framework, this risk would be mitigated.

Another source of risk in the marriage market stems from the way I set up the married couple problem. Spouses are not allowed to bargain over the share of household utility they receive. Instead I emphasize economies of scale in consumption (through consumption equivalence scales),

\footnotetext{
${ }^{9}$ The assumption of no prenatal investments and the assumption of no genetic persistence in skill are distinct. For an excellent discussion of studies on the role of prenatal care, see Corman, Dave, and Reichman (2018). For a discussion of studies on the relationship between genes and cognitive skills, see National Scientific Council on the Developing Child (2010) and the citations therein.
} 
and gains from teamwork in investment in the couple's children through the skill technology. By contrast, a framework with bargaining would have allowed the spouse who gains the most from the match relative to being single to convince their potential spouse to marry them, with the promise of a larger fraction of household utility in return (Choo and Siow (2006), Reynoso (2017)). These endogenous shares would act like prices. The missing market for transferring utility between spouses is absorbed into the risk faced on the marriage market, and increases the gains from insuring against a poor outcome there.

Finally, in the aggregate a larger labor income tax base allows the labor income tax rate to be lowered in equilibrium to balance the government budget constraint. The means that expansions in the labor income tax base due to the child care subsidy can increase welfare for everyone in society by allowing the labor income tax to decrease.

\section{Conclusion}

In this paper, I build and estimate a framework that incorporates a relevant dimension along which to target child care subsidies in general equilibrium: family structure. Specifically, I allow prices, tax rates, the distribution of skill, and family formation to adjust endogenously in response to the child care subsidy. After estimating the technologies that single mothers and couples use to invest in their children, I apply the model to compare the welfare effects of universal subsidies to child care with subsidies targeted at the poor and to one-parent families with young children. I find that universal child care subsidies yield ex ante welfare gains of 5.9 percentage points in consumption equivalent units. These gains are 3.5 and 3.9 percentage points higher than subsidies to single mothers or the the poor, respectively. Compared to the two targeted subsidies I consider, universal subsidies are a better policy because they more fully insure newborns against the risks they face without disincentivizing skill investment.

This analysis could be extended to incorporate the effects of different eligibility rules over the transition from one steady-state to another. The analysis I conduct here is a comparison of steadystates: in the transition, gains from expansions in the population's distribution of skill will take time to realize, and generations who incur the costs of funding the subsidy without themselves 
enjoying the gains in skill it affords will see welfare losses. A steady-state comparison does not account for these dynamics. In addition, the non-parental care sector can be further elaborated, so that the elasticity of supply for non-parental care can be disciplined and its implications for large-scale subsidies examined (Blau (1993)). Finally, more structure could be imposed on the single father problem specification. Most of the work done on this front has focused on divorced spouses, rather than on those who never marry, as in my model (Del Boca and Flinn (1995), Tartari (2015)).

As it stands, this paper provides a useful framework for analyzing child care policies in an environment with heterogeneous family structures, with implications for how such policies will affect the marriage rate, tax levels, and welfare. This paper also provides new estimates on how parental time inputs interact with non-parental child care time to affect child skill accumulation during early childhood, for one- and two-parent families. 


\section{References}

Abadie, A., S. Athey, G. W. Imbens, and J. Wooldridge (2017). When should you adjust standard errors for clustering? Working Paper.

Abbott, B. (2018). The substitutability of parental investments of time and expenditure. Working Paper.

Abbott, B., G. Gallipolli, C. Meghir, and G. Violante (2018). Education policy and intergenerational transfers in equilibrium. Cowles Foundation Discussion Paper No. 1887R2.

Agostinelli, F. and M. Wiswall (2016). Identification of dynamic latent factor models: The implications of re-normalization in a model of child development. NBER Working Paper No. 22441.

Aguiar, M. and E. Hurst (2007). Measuring trends in leisure: The allocation of time over five decades. The Quarterly Journal of Economics 122(3), 969-1006.

Anderson, M. L. (2008). Multiple inference and gender differences in the effects of early intervention: A reevaluaton of the abecedarian, perry preschool, and early training projects. Journal of the American Statistical Association 103(484), 1481-1495.

Andreoni, J. (1990). Impure altruism and donations to public goods: A theory of warm-glow giving. The Economic Journal 100(401), 464-477.

Baker, M. (2011). Innis lecture: Universal early childhood interventions: what is the evidence base? Canadian Journal of Economics 44(4), 1069-1105.

Baker, M., J. Gruber, and K. Milligan (2008). Universal childcare, maternal labor supply, and family well-being. Journal of Political Economy 116(4), 709-745.

Becker, G. S. and N. Tomes (1979). An equilibrium theory of the distribution of income and intergenerational mobility. The Journal of Political Economy, 1153-1189.

Berlinski, S., S. Galiani, and P. Gertler (2009). The effect of pre-primary education on primary school performance. Journal of Public Economics 93(1-2), 219-234.

Blau, D. and J. Currie (2006). Pre-school, day care, and after-school care: Who's minding the kids? 
In E. A. Hanushek and F. Welch (Eds.), Handbook of the Economics of Education, Chapter 20, pp. 1163-1276. Elsevier.

Blau, D. M. (1993). The supply of child care labor. Journal of Labor Economics 11(2), 324-347.

Browning, E. K. (1999). The myth of fiscal externalities. Public Finance Review 27(1), 3-18.

Buchanan, J. M. (1966). Externality in tax response. Southern Economic Journal 33(1), 35-42.

Caucutt, E. and L. Lochner (2017). Early and late human capital investments, borrowing constraints, and the family. HCEO Working Paper Series No. 2017-040.

Choo, E. and A. Siow (2006). Who marries whom and why. Journal of Political Economy 114(1), 175-201.

Corman, H., D. M. Dave, and N. Reichman (2018). Effects of prenatal care on birth outcomes: Reconcicling a messy literature. NBER Working Paper No. 24885.

Cunha, F. and J. Heckman (2007). The technology of skill formation. AEA Papers $\mathcal{E}$ Proceedings 97(2), 32-47.

Cunha, F. and J. Heckman (2008). Formulating, identifying and estimating the technology of cognitive and noncognitive skill formation. The Journal of Human Resources 43(4), 738-782.

Cunha, F., J. Heckman, and S. Schennach (2010). Estimating the technology of cognitive and noncognitive skill formation. Econometrica 78(3), 883-931.

Daruich, D. (2017). The macroeconomic consequences of early childhood development policies. Job Market Paper.

De Nardi, M. (2004). Wealth inequality and intergenerational links. Review of Economic Studies 71, 743-768.

Del Boca, D., C. Flinn, and M. Wiswall (2014). Household choice and child development. Review of Economic Studies 81, 137-185.

Del Boca, D. and C. J. Flinn (1995). Rationalizing child-support decisions. The American Economic Review 85(5), 1241-1262. 
Garcia, J. L., J. J. Heckman, D. E. Leaf, and M. J. Prados (2016). The life-cycle benefits of an influential early childhood program. NBER Working Paper No. 22993.

Garcia, J. L., J. J. Heckman, and A. L. Ziff (2018). Gender differences in the benefits of an influtential early childhood program. European Economic Review 109, 9-22.

Gayle, G.-L., G. Limor, and M. Soytas (2017). What is the source of the intergenerational correlation in earnings? Working Paper.

Guner, N., R. Kaygusuz, and G. Ventura (2016). Child-related transfers, household labor supply and welfare. Working Paper.

Gupta, N. D. and M. Simonsen (2010). Non-cognitive child outcomes and universal high quality child care. Journal of Public Economics 94(1-2), 30-43.

Guvenen, F. and M. Rendall (2015). Women's emancipation through education: A macroeconomic analysis. Review of Economic Dynamics 18(4), 931-956.

Havnes, T. and M. Mogstad (2014). Is universal child care leveling the playing field? Journal of Public Economics 127, 100-114.

Heathcote, J., F. Perri, and G. L. Violante (2010). Unequal we stand: An empirical unalysis of economic inequality in the united states, 1967-2006. Review of Economic Dynamics 13(1), 15-51.

Kottelenberg, M. J. and S. F. Lehrer (2014). The gender effects of universal child care in canada: Much ado about boys? Working Paper.

Kottelenberg, M. J. and S. F. Lehrer (2017). Targeted or universal coverage? assessing heterogeneity in the effects of universal childcare. Journal of Labor Economics.

Lee, S. Y. and A. Seshadri (2018). On the intergenerational transmission of economic status. Journal of Public Economics (forthcoming).

Lochner, L. J. and A. Monge-Naranjo (2011). The nature of credit constraints and human capital. The American Economic Review, 2487-2529.

McGrattan, E. R. and E. C. Prescott (2017). On financing retirement with an aging population. Quantitative Economics 8(1), 75-115. 
National Scientific Council on the Developing Child (2010). Early experiences can alter gene expression and affect long-term development: Working paper no. 10.

Restuccia, D. and C. Urrutia (2004). Intergenerational persistence of earnings: The role of early and college education. American Economic Review 94(5), 1354-1378.

Reynoso, A. (2017). The impact of divorce laws on equilibrium in the marriage market. Job Market Paper.

Rustichini, A., W. G. Iacono, and M. McGue (2016). The contribution of skills and family background to educational mobility. The Scandinavian Journal of Economics 00(0), 1-30.

Tartari, M. (2015). Divorce and the cognitive achievement of children. International Economic Review 56(2), 597-645.

Todd, P. E. and K. I. Wolpin (2003). On the specification and estimation of the production function for cognitive achievement. The Economic Journal 113(485), F3-F33. 


\section{A Appendix}

\section{A.1 Motivating Regressions for Model Specification}

To motivate my model's specification, this section provides several regressions using ECLS-B data.

Table 16: Predicting Initial Skill with Family Attributes + Prenatal Care

\begin{tabular}{|c|c|c|c|}
\hline Child is Female & $\begin{array}{c}(1) \\
\text { Married Couples } \\
0.174^{*} \\
(0.0690)\end{array}$ & $\begin{array}{c}(2) \\
\text { Single Mothers } \\
-0.0504 \\
(0.0871)\end{array}$ & $\begin{array}{c}(3) \\
\text { All Mothers } \\
0.116^{*} \\
(0.0559)\end{array}$ \\
\hline B.A.: Mother & $\begin{array}{c}-0.0663 \\
(0.0752)\end{array}$ & $\begin{array}{c}-0.271^{*} \\
(0.124)\end{array}$ & $\begin{array}{c}-0.130^{*} \\
(0.0611)\end{array}$ \\
\hline B.A.: Father & $\begin{array}{c}-0.106 \\
(0.0778)\end{array}$ & & \\
\hline Hourly Wage: Mother & $\begin{array}{c}0.0393 \\
(0.0338)\end{array}$ & $\begin{array}{c}-0.0792 \\
(0.0407)\end{array}$ & $\begin{array}{c}0.0206 \\
(0.0328)\end{array}$ \\
\hline Hourly Wage: Father & $\begin{array}{c}0.0517 \\
(0.0283)\end{array}$ & & \\
\hline Month Began Prenatal Visits & $\begin{array}{c}0.0121 \\
(0.0387)\end{array}$ & $\begin{array}{r}-0.00857 \\
(0.0425)\end{array}$ & $\begin{array}{l}0.00789 \\
(0.0301)\end{array}$ \\
\hline No. Prenatal Visits & $\begin{array}{c}0.0166 \\
(0.0437)\end{array}$ & $\begin{array}{c}-0.0192 \\
(0.0490)\end{array}$ & $\begin{array}{c}-0.00254 \\
(0.0340)\end{array}$ \\
\hline Single Mother & & & $\begin{array}{c}0.0201 \\
(0.0614)\end{array}$ \\
\hline Constant & $\begin{array}{c}4.277^{* * *} \\
(0.163)\end{array}$ & $\begin{array}{c}4.693^{* * *} \\
(0.194)\end{array}$ & $\begin{array}{c}4.428^{* * *} \\
(0.131)\end{array}$ \\
\hline $\begin{array}{l}R^{2} \\
\text { N_sub }\end{array}$ & $\begin{array}{c}0.0151 \\
2900\end{array}$ & $\begin{array}{c}0.0141 \\
1350\end{array}$ & $\begin{array}{c}0.0085 \\
4250\end{array}$ \\
\hline
\end{tabular}

In Table 16, I regress a child's test scores at age 4 on family attributes, child initial skill, and child gender. I do this separately for children of married couples and single mothers, because family attributes include those of the father for the former but not the latter (different explanatory variables). 
Table 17: Time Investments by Child Gender

\begin{tabular}{|c|c|c|c|c|}
\hline & \multicolumn{2}{|c|}{ Married Couples } & \multicolumn{2}{|c|}{ Single Mothers } \\
\hline & $\begin{array}{c}(1) \\
\text { Tot. Parental Time }\end{array}$ & $\begin{array}{c}(2) \\
\text { N Time }\end{array}$ & $\begin{array}{l}(3) \\
\text { N Time }\end{array}$ & $\begin{array}{c}(4) \\
\text { Total Time }\end{array}$ \\
\hline Child is Female & $\begin{array}{l}-0.0845 \\
(0.212)\end{array}$ & $\begin{array}{l}-0.216 \\
(0.782)\end{array}$ & $\begin{array}{l}-1.156 \\
(0.850)\end{array}$ & $\begin{array}{l}0.0434 \\
(0.499)\end{array}$ \\
\hline Child Test Score $[0,1]$ & $\begin{array}{c}8.528^{* * *} \\
(0.598)\end{array}$ & $\begin{array}{c}8.281^{* * *} \\
(2.219)\end{array}$ & $\begin{array}{c}1.023 \\
(2.477)\end{array}$ & $\begin{array}{c}9.945^{* * *} \\
(1.389)\end{array}$ \\
\hline B.A.: Father & $\begin{array}{c}2.104^{* * *} \\
(0.250)\end{array}$ & $\begin{array}{l}-0.895 \\
(0.904)\end{array}$ & & \\
\hline B.A.: Mother & $\begin{array}{l}1.850^{* * *} \\
(0.247)\end{array}$ & $\begin{array}{l}2.745^{* *} \\
(0.881)\end{array}$ & $\begin{array}{c}1.578 \\
(1.473)\end{array}$ & $\begin{array}{c}3.484^{* * *} \\
(0.556)\end{array}$ \\
\hline Hourly Wage: Father & $\begin{array}{c}0.0105 \\
(0.00588)\end{array}$ & $\begin{array}{c}-0.0248^{*} \\
(0.0118)\end{array}$ & & \\
\hline Hourly Wage: Mother & $\begin{array}{c}0.00922^{*} \\
(0.00369)\end{array}$ & $\begin{array}{c}-0.0146 \\
(0.0131)\end{array}$ & $\begin{array}{c}-0.0638^{* *} \\
(0.0244)\end{array}$ & $\begin{array}{c}-0.0122 \\
(0.0107)\end{array}$ \\
\hline Constant & $\begin{array}{c}-2.921^{* * *} \\
(0.824)\end{array}$ & $\begin{array}{c}10.59^{* * *} \\
(3.134)\end{array}$ & $\begin{array}{c}29.68^{* * *} \\
(3.443)\end{array}$ & $\begin{array}{c}18.85^{* * *} \\
(1.905)\end{array}$ \\
\hline$R^{2}$ & .13 & $1.1 \mathrm{e}-02$ & $5.0 \mathrm{e}-03$ & $1.7 \mathrm{e}-02$ \\
\hline
\end{tabular}

In Tables 17 and 18, I report regression analyses I use to motivate two modelling assumptions: parents do not target investments by child gender, and initial skill endowments (at 9 months) affect skill outcomes later in life (at 4 years of age). Table 17 reports four models, each with a time input choice as the dependent variable. The first two are for married couples, the second two for single mothers. Time investments are predicted by attributes of the parents (hourly wages and educational attainment) and attributes of the child (current skill). Child gender is not a statistically significant predictor of parental time inputs, according to Table 17. There is some evidence in other studies that parenting behavior and treatment effects of the program vary by the gender of the child (see Garcia, Heckman, and Ziff (2018), Kottelenberg and Lehrer (2014)), but I do not see this my analysis. 
Table 18: Predicting Final Skill with Initial Skill + Time Investments

\begin{tabular}{lccc}
\hline \hline & $(1)$ & $(2)$ & $(3)$ \\
& Married Couples & Single Mothers & All \\
\hline Initial Test Score (9 Mo.): Stdzd & $0.138^{* * *}$ & $0.139^{* * *}$ & $0.130^{* * *}$ \\
& $(0.0389)$ & $(0.0350)$ & $(0.0373)$ \\
Hourly Wage: Mother & 0.0565 & $0.217^{* * *}$ & $0.123^{* *}$ \\
& $(0.0359)$ & $(0.0500)$ & $(0.0383)$ \\
Hourly Wage: Father & $0.0971^{* *}$ & & \\
& $(0.0312)$ & & \\
Child is Female & 0.108 & 0.135 & 0.0941 \\
& $(0.0619)$ & $(0.0738)$ & $(0.0636)$ \\
B.A.: Mother & $0.291^{* * *}$ & $0.662^{* * *}$ & $0.546^{* * *}$ \\
& $(0.0744)$ & $(0.113)$ & $(0.0651)$ \\
B.A.: Father & $0.441^{* * *}$ & & \\
& $(0.0788)$ & & \\
Constant & $0.851^{* * *}$ & & \\
& $(0.183)$ & $0.654^{* * *}$ & $1.005^{* * *}$ \\
$R^{2}$ & 0.1695 & $(0.160)$ & $(0.180)$ \\
\hline Observations & 2900 & 0.1273 & 0.1237 \\
\hline \hline Initial skill has predictive power. Units: standard deviations, except for indicators & \\
${ }^{*} p<0.05,{ }^{* *} p<0.01{ }^{* * *} p<0.001$ & & 2900 \\
Sample sizes rounded to nearest 50, following NCES requirements. & \\
\hline
\end{tabular}

Table 18 reports two models, one for married couples and one for single mothers. The dependent variable of both in both models is the final skill of the child at age 4. Explanatory variables include the initial skill of the child, gender of the child, indicators for parental educational attainment (BA or higher), and parental hourly wages. Initial test scores are statistically significant predictors for final test scores, and so are parental attributes related to their skill. This motivates including heterogeneity in initial skill endowments in my model. 


\section{A.1.1 Correlation of Child Skill and Family Income}

Table 19: Correlations of Skill and Family Income

\begin{tabular}{|c|c|c|}
\hline & $\begin{array}{c}(1) \\
\text { Test Score W1 }\end{array}$ & $\begin{array}{c}(2) \\
\text { Test Score W3 }\end{array}$ \\
\hline Family Income W1 & $\begin{array}{c}0.000114 \\
(0.000103)\end{array}$ & $\begin{array}{l}0.000651^{*} \\
(0.000254)\end{array}$ \\
\hline Flag: Present in model 2 samplel & $\begin{array}{l}-0.00677 \\
(0.00754)\end{array}$ & $\begin{array}{l}0 \\
(.)\end{array}$ \\
\hline Family Income W3 & & $\begin{array}{c}0.000693^{* * *} \\
(0.000204)\end{array}$ \\
\hline Test Score W1 (SD) & & $\begin{array}{l}0.141^{* *} \\
(0.0482)\end{array}$ \\
\hline Constant & $\begin{array}{c}1.453^{* * *} \\
(0.00733)\end{array}$ & $\begin{array}{l}1.004^{* * *} \\
(0.0705)\end{array}$ \\
\hline$R^{2}$ & .003 & .125 \\
\hline Observations & 1300 & 1500 \\
\hline Correlation & 0.04 & 0.33 \\
\hline Correlation p-value & .35 & 0 \\
\hline $\begin{array}{l}\text { Income in thousands of dollars. Test scor } \\
\text { Standard errors in parentheses. } \\
{ }^{*} p<0.05,{ }^{* *} p<0.01,{ }^{* * *} p<0.001\end{array}$ & es in standard devia & ion units. \\
\hline
\end{tabular}

Table 19 reports a slightly different version of the same qualitative points made with Tables 16, 17, and 18. The dependent variables in the two models are initial skill and final skill, with both family structures pooled. Initial income at 9 months has no predictive power for the initial skill score. At age 4, however, final skill can be predicted with income (both at age 9 months and 4 years) and the initial test score. In this table I also report the correlations of the dependent variable for the model (initial skill for model 1, final skill for model 2) with family income in the same period (initial and final, respectively). These correlations jump from zero to 0.33 . The latter number is my target for the correlation of child's skill at the end of childhood with family income. Note that the measure of family income I use here is income before labor income taxes but including transfers. I use the analogous object in the model in the internal calibration step. 


\section{A.2 Regression Results with Alternative Nestings}

As discussed in the body of this paper, alternative nestings of the CES function imply different restrictions on the elasticity of substitution between inputs. In this section of the Appendix, I report skill accumulation technology estimation results analogous to the one reported in the text, but for different nestings of the technology (Tables 20 and 21). For each nesting, I first give the functional form it assumes. In the titles of the different specifications, M stands for mother, F stands for father, and $\mathrm{N}$ stands for non-parental care. I give the innermost nesting of the couple problem (F,M) or $(\mathrm{F}, \mathrm{N})$, followed by the outermost one $(\mathrm{N}, \operatorname{not} \mathrm{N}),(\mathrm{M}$, not $\mathrm{M})$. The main qualitative points survive in the alternative nestings. The first alternative nesting presented below, however, does illustrate that restricting the substitutability of non-parental child care with mother and father time to be the same implies unrealistically large complementarity values for mother and father time.

Table 20: Nesting: $(\mathrm{F}, \mathrm{M})+(\mathrm{N}, \operatorname{not} \mathrm{N})$

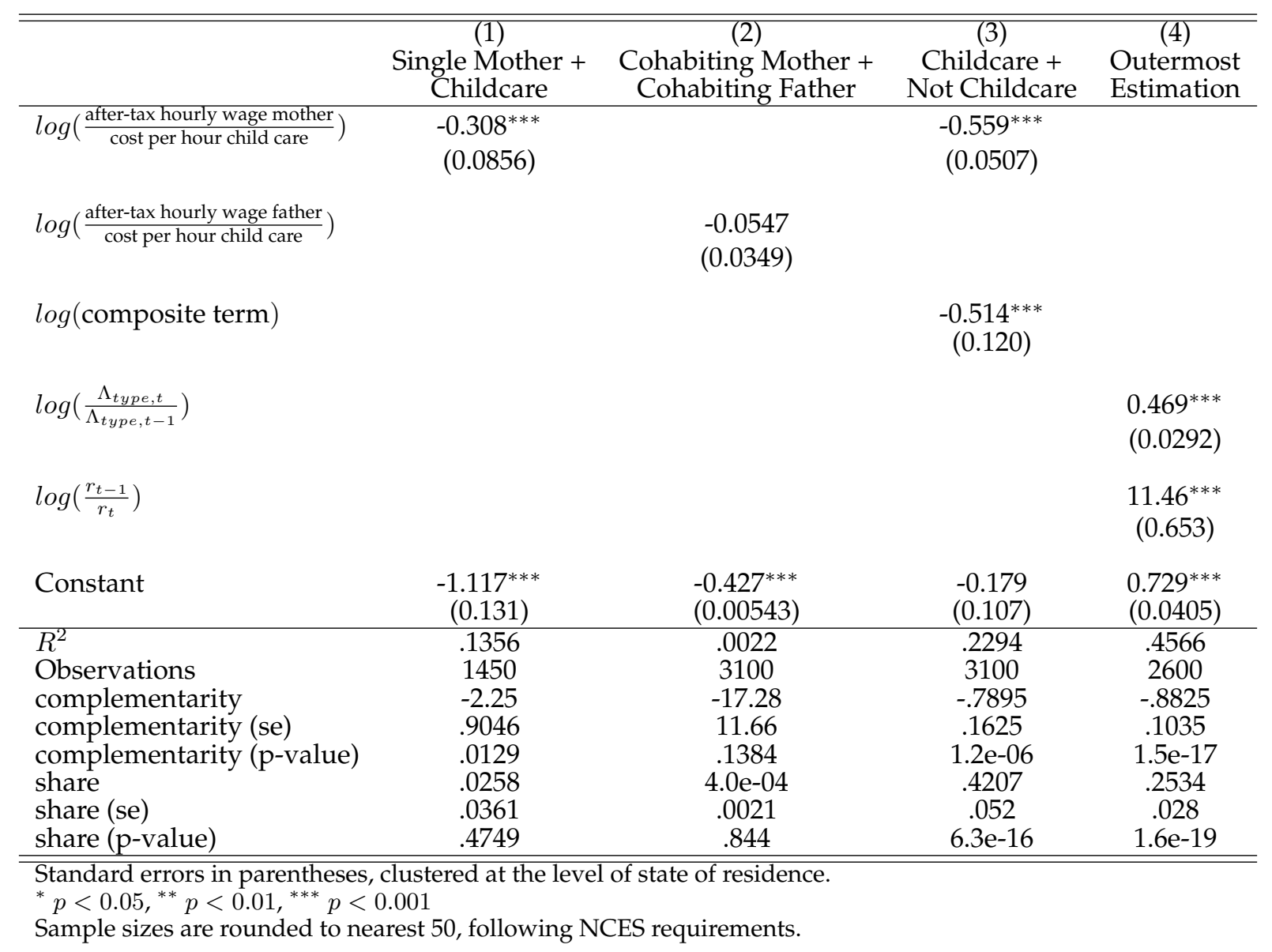


Table 21: Nesting: $(\mathrm{F}, \mathrm{N})+(\mathrm{M}$, not $\mathrm{M})$

\begin{tabular}{|c|c|c|c|c|}
\hline & $\begin{array}{c}\text { Single Mother + } \\
\text { Childcare }\end{array}$ & $\begin{array}{c}(2) \\
\text { Cohabiting Father }+ \\
\text { Childcare }\end{array}$ & $\begin{array}{c}\text { Cohabiting Mother }+ \\
\text { Not Cohabiting Mother }\end{array}$ & \begin{tabular}{l}
\multicolumn{1}{c}{$(4)$} \\
Outermost \\
Estimation
\end{tabular} \\
\hline $\log \left(\frac{\text { after-tax hourly wage mother }}{\text { cost per hour child care }}\right)$ & $\begin{array}{l}-0.298^{* *} \\
(0.0882)\end{array}$ & $\begin{array}{c}-0.363^{* * *} \\
(0.0657)\end{array}$ & & \\
\hline $\log ($ composite term $)$ & & $\begin{array}{c}-0.815^{* *} \\
(0.232)\end{array}$ & & \\
\hline $\log \left(\frac{\text { after-tax hourly wage father }}{\text { cost per hour child care }}\right)$ & & & $\begin{array}{c}-0.445^{* * *} \\
(0.0458)\end{array}$ & \\
\hline $\log \left(\frac{\Lambda_{t y p e, t}}{\Lambda_{\text {type }, t-1}}\right)$ & & & & $\begin{array}{l}0.493^{* * *} \\
(0.0251)\end{array}$ \\
\hline $\log \left(\frac{r_{t-1}}{r_{t}}\right)$ & & & & $\begin{array}{c}11.80^{* * *} \\
(0.662)\end{array}$ \\
\hline Constant & $\begin{array}{c}-1.132 * * * \\
(0.135)\end{array}$ & $\begin{array}{c}-0.313^{* *} \\
(0.0940)\end{array}$ & $\begin{array}{c}-1.015^{* * *} \\
(0.0650)\end{array}$ & $\begin{array}{l}0.746^{* * *} \\
(0.0430)\end{array}$ \\
\hline $\begin{array}{l}R^{2} \\
\text { Observations }\end{array}$ & .1262 & .227 & .1406 & .4925 \\
\hline $\begin{array}{l}\text { Observations } \\
\text { complementarity }\end{array}$ & $\begin{array}{l}1450 \\
-2351\end{array}$ & $\begin{array}{c}3100 \\
-1.757\end{array}$ & $\begin{array}{c}3100 \\
-1.248\end{array}$ & - 9714 \\
\hline $\begin{array}{l}\text { complementarity } \\
\text { complementarity (se) }\end{array}$ & $\begin{array}{l}-2.351 \\
.9908\end{array}$ & .4994 & .2314 & $\begin{array}{l}-.9714 \\
.0976\end{array}$ \\
\hline complementarity ( $\mathrm{p}$-value) & 0176 & $4.3 e-04$ & 7.0e-08 & $2.4 \mathrm{e}-23$ \\
\hline share & .022 & 2768 & .0927 & .2296 \\
\hline share (se) & .0339 & .0607 & .032 & .0236 \\
\hline share (p-value) & 5157 & $5.2 \mathrm{e}-06$ & .0038 & $2.6 \mathrm{e}-22$ \\
\hline
\end{tabular}

\section{A.3 Description of Data Sources}

\section{A.3.1 The Early Childhood Education Longitudinal Study, Birth Cohort}

The ECLS-B follows a nationally representative sample of families with a child who was 9 months old in 2001. It was designed and collected by the United States Department of Education. Using birth-certificate data from the National Center for Health Statistics, over 14,000 births were selected within Primary Sampling Units. Children of mothers younger than 15 were excluded from the sampling frame. There are 5 waves: wave 1 is the 9 -month old data collection round, wave 2 occurs at 2 years, wave 3 at 4 years, and waves 4 and 5 at kindergarten entry. If the focal child was not in kindergarten when wave 4 was collected, the surveyors went back and collected data the next year when they were enrolled. In addition, if a child repeated kindergarten, their scores were also collected in wave 5 in addition to wave 4 . Each wave contains several instruments; 
these are different self-administered questionnaires (SAQs) for different people in the child's life, in addition to the child-level data. Table 22 summarizes these instruments in each wave of the survey.

Table 22: The Structure of the ECLS-B

\begin{tabular}{|c|c|c|c|c|}
\hline Instrument & Wave 1 & Wave 2 & Wave 3 & Wave $4+5$ \\
\hline 1. & Parent Interview & Parent Interview + SAQ & Parent SAQ & Parent SAQ \\
\hline 2. & Resident Father & Resident Father SAO & Resident Father SAO & ECEP Interview ${ }^{1}$ \\
\hline 3. & Nonresident Father & Nonresident Father SAQQ & Preschool Center Director SAQ & Teacher \\
\hline 4. & & Child Care Provider & Preschool ECEP SAQ ${ }^{1}$ & WECEP Interview $^{2}$ \\
\hline
\end{tabular}

\footnotetext{
${ }^{1}$ Early Care and Education Provider

${ }^{2}$ Wrap-around Care Early Care and Education Provider
}

In each wave of the survey, the primary care provider (usually the mother) and the resident father fill out detailed questionnaires on the activities they do with their kids and at what frequency (once a week, twice a week, once a month, etc.). In addition, they report age, educational attainment, income, hours worked, the number of hours the child spent in non-parental care, what type of care that was (relative, non-relative, center-based), and the cost of that care.

I define quality time as the total amount of time spent (1) reading to the child (2) talking with or listening to the child (3) singing to the child. To map from frequencies of activities to levels of quality time supplied by parents, I impute amount of time per activity using data from the ATUS. The imputation uses common characteristics observed across both samples: gender, marital status (married/cohabiting or single), labor force status, and educational attainment. Here educational attainment is less than a college degree, or a college degree or more. For hourly wages, I use time spent working and income to compute the pre-tax levels, and then Table 2 of McGrattan and Prescott (2017) to correct for labor income taxes. For hourly prices of non-parental care, I use total cost of child care and total hours in child care for the primary source of non-parental care reported by the primary caregiver of the survey child subject.

\section{A.3.2 American Time Use Survey}

I use a pooled sample from the ATUS from 2003 to 2016, which is provided with CPS variables on age, gender, marital status, labor force status, educational attainment and family structure along 
with a time diary. I restrict the sample to parents who are between 15 and 55, with a child 4 years or younger. I use information on gender, marital status (married/cohabiting or single), labor force status, and educational attainment, where educational attainment is recoded as less than a college degree or a college degree and higher.

\section{A.3.3 Imputation}

In the baseline estimation, I focus on parents of children under 4 years old who are aged 55 and younger. In the ECLS-B this is respondents of waves 1 to 3 . I additionally restrict observations to those who report age, educational attainment, and how often they participated in the activities of interest explained above. I further restrict the sample by excluding outliers: I only use those observations for whom after-tax hourly wages are greater than 0.1 cents and no greater than 200 dollars an hour. Finally, I only consider families observed in each and all of the first three waves of the survey, so that a family-specific mean can be computed for the fixed effects estimator.

Given these characteristics, I find survey-weighted averages of time spent on an activity for those who report engaging in it. The activities whose average duration I tabulate are (1) time spend reading to your child (2) time spent talking and listening. I assign the level of time spent reading and talking and listening to their respective activities in the ECLS-B; additionally, I assign the level of time spent talking and listening to the singing activity reported by parents in the ECLS-B. I do this because there is no singing activity reported in the ATUS.

Once I have imputed time levels per activity, I aggregate levels of quality time per parent in each family in each wave. This gives me quality time investments, non-parental time investments, after-tax hourly wages, and non-parental child care prices at the child-family pair and wave level. With this information, I can implement my estimation.

\section{A.3.4 Summary Statistics for Raw and Estimation Sample in ECLS-B and Imputation Sample in ATUS}

In the following two subsections I report sample summary statistics for the raw data and the estimation sample. For the raw data I report by wave of the sample, and for the estimation sample I pool all the viable observations in the three waves and report statistics on those. I also report 
summary statistics for the ATUS sample I used to impute time levels to observed frequencies of activities in the ECLS-B sample.

\section{A.3.5 Summary Statistics ECLS-B}

The following summary statistics describe the ECLS-B data, pooled across family structures after the imputation from the ATUS, by wave and before data cleaning. The population moments I use in the internal calibration for the fraction of parents who are single mothers comes from this sample. The fraction in the sample that also reports variables necessary for estimation is larger than these population moments. Notice that the fraction below $185 \%$ of the poverty line in the pooled sample is quite high, at $50 \%$. This drop to $40 \%$ by the time the child is age 4 . Averages here include observations for which the response is 0 . This explains why the average age of the father is now lower than the mother's.

Table 23: Summary Statistics Raw Sample ECLS-B: Wave 1

\begin{tabular}{lccccc}
\hline \hline & \multicolumn{5}{c}{ Wave 1} \\
& Obs. & mean & sd & min & max \\
\hline Education Time Father: Hours per Week & 10700 & 2.88 & 3.37 & 0.00 & 12.67 \\
Education Time Mother: Hours per Week & 10700 & 7.43 & 3.15 & 0.00 & 12.75 \\
Below Poverty Line & 10700 & 0.26 & 0.44 & 0.00 & 1.00 \\
Below 185\% of Poverty Line & 10700 & 0.50 & 0.50 & 0.00 & 1.00 \\
Marriage Rate & 10700 & 0.64 & 0.48 & 0.00 & 1.00 \\
Cohabitation Rate & 10700 & 0.78 & 0.42 & 0.00 & 1.00 \\
Single Mother & 10700 & 0.21 & 0.40 & 0.00 & 1.00 \\
Nonparental Care: Hours per Week & 10700 & 14.32 & 18.53 & 0.00 & 70.00 \\
Ratio of Time: Father/Mother & 10400 & 0.44 & 0.64 & 0.00 & 9.93 \\
Ratio of Time: Mother/Childcare & 5200 & 0.54 & 0.96 & 0.00 & 12.75 \\
Hourly Pay Mother, After Tax & 5000 & 11.13 & 21.46 & 0.00 & 788.00 \\
Hourly Pay Father, After Tax & 6600 & 13.43 & 17.12 & 0.00 & 827.40 \\
Cost per hour childcare & 3500 & 3.41 & 177.25 & 0.00 & 10479.04 \\
After-tax hourly wage mother & 8250 & 1.25 & 3.37 & 0.00 & 99.50 \\
Hourly Cost Childcare & 10700 & 28.46 & 6.64 & -1.00 & 68.00 \\
Age Res. Mother & 10700 & 25.16 & 14.83 & -9.00 & 75.00 \\
Age Res. Father & 10700 & 0.26 & 0.44 & 0.00 & 1.00 \\
Mother: BA or higher & 10700 & 0.25 & 0.43 & 0.00 & 1.00 \\
Father: BA or higher & & & & & \\
\hline \hline
\end{tabular}

Sample sizes rounded to nearest 50, following NCES requirements. 
Table 24: Summary Statistics Raw Sample ECLS-B: Wave 2

\begin{tabular}{lccccc}
\hline \hline & & \multicolumn{3}{c}{ Wave 2} \\
& Obs. & mean & sd & min & max \\
\hline Education Time Father: Hours per Week & 10700 & 3.41 & 4.12 & 0.00 & 12.67 \\
Education Time Mother: Hours per Week & 10700 & 7.94 & 4.04 & 0.00 & 12.75 \\
Below Poverty Line & 10700 & 0.00 & 0.00 & 0.00 & 0.00 \\
Below 185\% of Poverty Line & 10700 & 0.00 & 0.00 & 0.00 & 0.00 \\
Marriage Rate & 10700 & 0.59 & 0.49 & 0.00 & 1.00 \\
Cohabitation Rate & 10700 & 0.69 & 0.46 & 0.00 & 1.00 \\
Single Mother & 10700 & 0.19 & 0.39 & 0.00 & 1.00 \\
Nonparental Care: Hours per Week & 10700 & 14.04 & 18.51 & 0.00 & 80.00 \\
Ratio of Time: Father/Mother & 9350 & 0.46 & 0.57 & 0.00 & 9.83 \\
Ratio of Time: Mother/Childcare & 4800 & 0.48 & 0.76 & 0.00 & 12.67 \\
Hourly Pay Mother, After Tax & 5100 & 11.64 & 26.28 & 0.00 & 1004.70 \\
Hourly Pay Father, After Tax & 6200 & 15.14 & 52.93 & 0.00 & 3546.00 \\
Cost per hour childcare & 3900 & 348.68 & 21649.58 & 0.00 & 1345064.75 \\
After-tax hourly wage mother & 9000 & 1.05 & 2.31 & 0.00 & 64.00 \\
Hourly Cost Childcare & 9850 & 29.79 & 7.02 & -1.00 & 70.00 \\
Age Res. Mother & 9850 & 26.20 & 15.38 & -9.00 & 76.00 \\
Age Res. Father & 10700 & 0.33 & 0.47 & 0.00 & 1.00 \\
Mother: BA or higher & 10700 & 0.32 & 0.47 & 0.00 & 1.00 \\
Father: BA or higher & & & & \\
\hline \hline
\end{tabular}

Sample sizes rounded to nearest 50, following NCES requirements.

Table 25: Summary Statistics Raw Sample ECLS-B: Wave 3

\begin{tabular}{lccccc}
\hline \hline & & & Wave 3 & \\
& Obs. & mean & sd & min & max \\
\hline Education Time Father: Hours per Week & 10700 & 2.22 & 2.80 & 0.00 & 12.67 \\
Education Time Mother: Hours per Week & 10700 & 5.15 & 3.78 & 0.00 & 12.75 \\
Below Poverty Line & 10700 & 0.20 & 0.40 & 0.00 & 1.00 \\
Below 185\% of Poverty Line & 10700 & 0.39 & 0.49 & 0.00 & 1.00 \\
Marriage Rate & 10700 & 0.52 & 0.50 & 0.00 & 1.00 \\
Cohabitation Rate & 10700 & 0.59 & 0.49 & 0.00 & 1.00 \\
Single Mother & 10700 & 0.17 & 0.37 & 0.00 & 1.00 \\
Nonparental Care: Hours per Week & 10700 & 16.53 & 16.52 & 0.00 & 96.00 \\
Ratio of Time: Father/Mother & 8100 & 0.48 & 0.54 & 0.00 & 6.57 \\
Ratio of Time: Mother/Childcare & 7100 & 0.44 & 0.60 & 0.00 & 12.67 \\
Hourly Pay Mother, After Tax & 5000 & 12.58 & 23.18 & 0.00 & 1063.80 \\
Hourly Pay Father, After Tax & 5400 & 15.95 & 16.97 & 0.00 & 506.57 \\
Cost per hour childcare & 3200 & 253.07 & 10139.75 & 0.00 & 419839.25 \\
After-tax hourly wage mother & 7500 & 2.19 & 3.83 & 0.00 & 64.71 \\
Hourly Cost Childcare & 9000 & 32.28 & 7.56 & -1.00 & 82.00 \\
Age Res. Mother & 9000 & 28.16 & 16.36 & -9.00 & 83.00 \\
Age Res. Father & 10700 & 0.41 & 0.49 & 0.00 & 1.00 \\
Mother: BA or higher & 10700 & 0.39 & 0.49 & 0.00 & 1.00 \\
Father: BA or higher & & & & & \\
\hline \hline
\end{tabular}

Sample sizes rounded to nearest 50, following NCES requirements.

\section{A.3.6 ATUS Imputation Data}

For the imputation of time levels per activity, I used a pooled sample from the ATUS 2003-2016. I divide parents of children 3 and under into bins by labor force status, educational attainment, marital status and gender. For each bin, I find the average time spent reading, doing educational 
activities, and playing with each bin's children conditional on having done each activity during the observation period. This is the level I assign to the ECLS-B sample for time spent talking and listening or time spent singing (educational hours) or time spent reading (reading hours). Table 23 displays group averages.

The population of these groups in the ATUS, even over such a large sample period, can be quite small. For example, only 85 married men not in the labor force with less than a BA reported reading to their children under 3 between 2003-2016. There were 35 single women with greater than a college degree (BA), not in the labor force, who reported spending educational time with their children aged 3 and under.

Table 26: ATUS Imputation: Group Means (hours per week)

\begin{tabular}{lcccc}
\hline & \multicolumn{2}{c}{ Reading } & \multicolumn{2}{c}{ Educational } \\
Group & Hours & Obs & Hours & Obs \\
\hline Married Male in LF It BA & 0.512 & 612 & 0.459 & 371 \\
Married Male in LF gte BA & 0.468 & 1318 & 0.528 & 337 \\
Married Male not in LF lt BA & 0.694 & 85 & 0.359 & 43 \\
Married Female in LF lt BA & 0.457 & 778 & 0.603 & 472 \\
Married Female in LF gte BA & 0.458 & 1799 & 0.565 & 601 \\
Married Female not in LF lt BA & 0.556 & 860 & 0.640 & 580 \\
Married Female not in LF gte BA & 0.565 & 1062 & 0.521 & 413 \\
Single Female in LF lt BA & 0.458 & 273 & 0.541 & 198 \\
Single Female in LF gte BA & 0.361 & 134 & 0.326 & 44 \\
Single Female not in LF lt BA & 0.501 & 195 & 0.670 & 194 \\
Single Female not in LF gte BA & 0.621 & 34 & 0.409 & 35 \\
\hline
\end{tabular}

\section{A.3.7 Measures of Skill in the ECLS-B}

There are three skill measures from the ECLS-B that I use in the regressions presented in Tables 16 to 18 , one for waves 1,2 and 3. In wave 1, the ECLS-B reports test scores from the Bayley Short Form - Research Edition, which is a shortened version of the Bayley Scaled of Infant Development, Second Edition (BSF-R and BSID-II, respectively). The latter exam is the standard one for measuring development in children under 42 months of age. The BSF-R is a shortened version of the BSID-II, asking only some of the questions. Its scores are then re-scaled to make them comparable with scores from children who receive the BSID-II. For the initial test score variable used in Tables 16 to 19, I take the scale scores of the BSF-R at 9 months (in the first wave of the ECLS-B), which are reported both for mental and motor development. I then take the average of the two, and next I standardize them to lie between 0 and 1 . For the test score value in the second wave, used in 
Table 17, I do the same procedure with the BSF-R scores recorded at 2 years of age (in wave 2 of the ECLS-B). By age 5, when the child is 48 months, the BSID-II and its subset exam the BSF-R are no longer an age-appropriate measures of development for children. Instead, the ECLS-B reports a new assessment battery that covers cognitive development in the domains of language, literacy, color knowledge, and mathematics. This is reported as the ECLS-B Direct Cognitive Assessment in several formats. I use the overall scale score of the Direct Cognitive Assessment and standardize it to lie between 0 and 1 . This is the final test score used in the regressions of Table 18.

\section{A.4 Child Support Payments from Single Fathers and Transfers as a Fraction of GDP}

To discipline child support payments from single fathers, I use Table 3.12 from NIPA, Census tabulations on family counts in 2001, and the US Census Bureau report "Custodial Mothers and Fathers and Their Child Support: 2001". From US Census counts, I set the number of families in the US in 2001 to $71,787,347$. Table 1.1.5 from NIPA gives the total amount of transfers in 2001 by components: I sum federal benefits from social insurance funds, Supplemental Nutrition Assistance Program (SNAP), supplemental security income, and refundable tax credits and other (which includes payments to nonprofit instutitions and student loans, among other categories). This totals 815 billion dollars. Combined with the number of families, this gives about 11,354 dollars per family in transfers in 2001. From the Census Bureau report, the average level of child support received by custodial mothers was 3,160 dollars in 2001. This makes the average child support payment due as a fraction of the average transfer to families about 0.28. Transfers as a fraction of GDP use Table 1.1.5 from NIPA in addition to Table 3.12. Total GDP in 2001 was 10,581 in billions of dollars. After rounding, this makes transfers as a fraction of $8 \%$ of GDP.

\section{A.5 Labor Supply in the CPS}

To calculate the average labor supply for the data moment in the internal calibration, I use Annual Social and Economic Supplement of the CPS from 2000. I define hours worked per week as the self-reported hours worked last week. I assign a 0 for this value for those who report not being in the labor force. I then find the average hours worked per week, weighted by the supplement household weight, for those between the ages of 20 and 80 with children under 5 whose marital 
status is reported as either "never married/single" or "married, spouse present". This is a sample of 11,771 individuals, $53 \%$ of whom are women and $88 \%$ of whom are married. The resulting moment for average labor supply in this group is 31 hours per week, or 0.31 when expressed as a fraction of 100 disposable hours per week.

\section{A.6 Earnings Distribution: Model v. Data}

In Table 27, I show how the implied earnings distribution of the baseline equilibrium compares with that found in the CPS for 2001 by Heathcote, Perri, and Violante (2010), referred to as "HSV" in the table. The p50/p10 ratio is quite close in the comparison, but the moments involving the 90th percentile are quite different in my model compared to the data. This is because the data is characterized by a tail in the income distribution, so that the 90th percentile of earnings is quite high relative to other percentiles in the distribution. In my model, by contrast, the 90th percentile is not that much higher than the median earnings level, and so the 90/50 ratio is small relative to it's empirical counterpart.

Table 27: Untargeted Moments (Model Fit)

\begin{tabular}{lccc} 
Moment & Source & Data & Model \\
\hline$\frac{\mathrm{p} 50}{\mathrm{p} 10}$ & HSV (CPS) & 3.2 & 2.9 \\
$\frac{\mathrm{p} 90}{\mathrm{p} 50}$ & HSV (CPS) & 2.4 & 1.5 \\
Gini & HSV (CPS) & 0.41 & 0.27
\end{tabular}

Notes: Table 27 compares moments of the empirical earnings distribution with the model baseline equilibrium.

\section{A.7 Spending on Child Care in the PSID}

A common argument in the investment aggregator, instead of child care time, is goods (or money) spent on the child (examples include Lee and Seshadri (2018), Daruich (2017) and Abbott (2018). In this section, I use tabulations from the 2001 PSID and 2002 PSID CDS to show how child care expenses contribute to total expenditures on the child. To do this, I construct four different measures of total expenditures on the child (Definitions 1 to 4 in the tables below, with each definition 
specified in the table footnote). Next, I find the fraction of each measure of total expenditures that comes from child care. My conclusion is that child care represents the main component of the expenditures on children in the PSID. In that sense, using time in non-parental child care as an input, and including expenditures on child care in the budget constraint of parents, can be viewed as narrowing in on the main component of expenditures on children and being specific about how it contributes to child skill accumulation (through time use).

Table 28: Definition 1

\begin{tabular}{lccc}
\hline \hline & & & \\
& mean & sd & count \\
\hline Ages [0,3] & 0.67 & 0.29 & 84 \\
Ages [0,5] & 0.68 & 0.28 & 146 \\
Ages [0,7] & 0.71 & 0.26 & 223 \\
Ages [0,9] & 0.70 & 0.27 & 260 \\
Ages [0,11] & 0.70 & 0.27 & 275 \\
\hline
\end{tabular}

Notes: Table 28 presents averages by age group for the fraction of total expenditure on children spent on child care. Definition 1 of total expenditures on children includes child care, money spent on toys, and money spent on school supplies

Table 29: Definition 2

\begin{tabular}{lccc}
\hline \hline & mean & sd & count \\
\hline Ages [0,3] & 0.55 & 0.28 & 84 \\
Ages [0,5] & 0.58 & 0.28 & 146 \\
Ages [0,7] & 0.61 & 0.26 & 223 \\
Ages [0,9] & 0.60 & 0.27 & 260 \\
Ages [0,11] & 0.60 & 0.27 & 275
\end{tabular}

Notes: Table 29 presents averages by age group for the fraction of total expenditure on children spent on child care. Definition 2 of total expenditures on children includes child care, money spent on toys, and money spent on school supplies. 
Table 30: Definition 3

\begin{tabular}{lccc}
\hline \hline & & & \\
& mean & sd & count \\
\hline Ages [0,3] & 0.49 & 0.27 & 83 \\
Ages [0,5] & 0.52 & 0.27 & 144 \\
Ages [0,7] & 0.55 & 0.26 & 220 \\
Ages [0,9] & 0.53 & 0.26 & 256 \\
Ages [0,11] & 0.53 & 0.26 & 271 \\
& & & \\
\hline \hline
\end{tabular}

Notes: Table 30 presents averages by age group for the fraction of total expenditure on children spent on child care. Definition 3 of total expenditures on children includes child care, money spent on toys, money spent on school supplies, money spent on vacations, and money spent on clothes.

Table 31: Definition 4

\begin{tabular}{lccc}
\hline \hline & mean & sd & count \\
\hline Ages [0,3] & 0.42 & 0.24 & 71 \\
Ages [0,5] & 0.43 & 0.24 & 126 \\
Ages [0,7] & 0.46 & 0.24 & 194 \\
Ages [0,9] & 0.44 & 0.23 & 229 \\
Ages [0,11] & 0.43 & 0.23 & 243 \\
& & & \\
\hline
\end{tabular}

Notes: Table 31 presents averages by age group for the fraction of total expenditure on children spent on child care. Definition 3 of total expenditures on children includes child care, money spent on toys, money spent on school supplies, money spent on vacations, money spent on clothes, and money spent on food.

\section{A.8 Single Fathers in the ECLS-B}

The ECLS-B provides a non-resident father questionnaire (NRQ) in the first two waves of the survey. In this section, I document six points about the sample of non-resident fathers that complete this survey as well as attributes of single mothers in the data. Sample counts for these tabulations reflect response rates for the questions of interest; here, I am not restricting by whether I also observe variables necessary for the skill accumulation technology estimation. In the statistics presented below, I use survey weights for the primary caregiver sample in wave 2. The main purpose of this section is to establish that relatiely few single fathers complete the survey, that those who do are not representative of the sample of single fathers, and that when they do complete the survey their answers and the answer's of their child's mother do not coincide. In addition, Table 33 makes an additional point about the marital status composition of single mothers: most were 
never married. This coincides with the timing and nature of the marriage market in my model.

The first three points are made in Tables 32 and 33. First, Table 32 shows that the response rate of non-resident fathers in each wave is about 1 in 3 . Second, Table 33 shows that the marital status of the corresponding single mother is about the same for the group of families with a completed NRQ and without a completed NRQ. Third, Table 33 also shows that most single mothers were never married (about 70\% and 65\% in the first and second wave of the survey, respectively). Since I do not model divorce, the composition of marital status in single mothers is important to check.

Table 32: Response Rate NR Questionnaire

\begin{tabular}{lcc}
\hline \hline & $\begin{array}{c}(1) \\
\text { Wave } 1\end{array}$ & $\begin{array}{c}(2) \\
\text { Wave } 2\end{array}$ \\
\hline Yes & 0.300 & 0.309 \\
No: Refusal & 0.292 & 0.179 \\
No: Not Permission & 0.194 & 0.270 \\
& & \\
No: Ineligible, Lack of Contact & 0.184 & 0.179 \\
& & \\
No: no NR & 0.0290 & 0.0596 \\
No: P not Biomother & & \\
Total & 0.000628 & 0.00303 \\
\hline Obs. & & \\
\hline
\end{tabular}

Table 32 displays response rates of non-resident fathers to the non-resident father survey in the ECLS-B. Slightly less than one-third of non-resident fathers respond. Sample sizes rounded to nearest 50, following NCES requirements. 
Table 33: Marital Status Composition of Mothers with NR fathers, by Questionnaire Response status

\begin{tabular}{|c|c|c|c|c|}
\hline & \multicolumn{2}{|l|}{ Wave 1} & \multicolumn{2}{|l|}{ Wave 2} \\
\hline & $\begin{array}{c}(1) \\
\text { Completed NRQ }\end{array}$ & $\begin{array}{c}(2) \\
\text { No NRQ }\end{array}$ & $\begin{array}{c}(3) \\
\text { Completed NRQ }\end{array}$ & $\begin{array}{c}(4) \\
\text { No NRQ }\end{array}$ \\
\hline Not Reported & 0 & 0.00369 & 0 & 0.000118 \\
\hline Married & 0.0640 & 0.0520 & 0.0921 & 0.0980 \\
\hline Separated & 0.107 & 0.119 & 0.105 & 0.0939 \\
\hline Divorced & 0.0909 & 0.0929 & 0.111 & 0.140 \\
\hline Widowed & 0.00320 & 0.0142 & 0.00195 & 0.0169 \\
\hline Never Married & 0.734 & 0.717 & 0.691 & 0.647 \\
\hline Not Biomother or Adoptive Parent & 0 & 0.000897 & 0 & 0.00439 \\
\hline Total & 1 & 1 & 1 & 1 \\
\hline Obs. & 650 & 1350 & 650 & 1400 \\
\hline
\end{tabular}

Table 33 displays the marital status composition of families where the biological parents are not cohabiting (single-parent families). The compositions are broken down by response status for the non-resident father questionnaire. Sample sizes rounded to nearest 50, following NCES requirements.

The next three points are made in Tables 34-38. For point four, Table 34 tabulates the days since the non-resident father last saw the child. Fathers who complete the NRQ have seen the child on average 1.5 days more recently than fathers who do not. Fifth, in Table 35 I tabulate responses to the question "In a typical week, does [the child's] father spend a lot, some, very little, or no time taking care of [the child]?", for families without a completed NRQ's (first column) and for those with an NRQ (second column). Fathers who completed the NRQ are more likely to be parenting with a resident primary caregiver who responds "A lot" to this question (35\% compared to 12\%). Relatedly, Table 36 shows that fathers who complete the NRQ are far more likely to have seen their child in the last month than fathers who did not complete the NRQ ( $90 \%$ versus $46 \%$ ). Sixth, in Tables 37 and 38 I tabulate the wave 2 responses to the question "When it comes to making major decisions, please tell me if [child's] father has no influence, some influence, or a great deal 
of incluence on such matters as child care?", separately for mothers (Table 37) in families without an NRQ (column 1) and those with an NRQ (column 2) and fathers (Table 28) who completed the NRQ. Fathers who completed the NRQ think they have a lot of influence; mothers with children whose fathers completed the NRQ say they have less influence than the fathers claim, although they report more influence more than do mothers in families without a completed NRQ.

Table 34: Wave 1: Number of Days since NRF last saw child

\begin{tabular}{lcc}
\hline & $(1)$ & $(2)$ \\
& No NRQ & Completed NRQ \\
\hline No. Days & 3.860 & 2.353 \\
\hline Obs. & 1300 & 650 \\
\hline \hline
\end{tabular}

Table 34 displays the average number of days since a non-resident father saw his child in the first wave of the survey, by response status to the non-resident father questionnaire. Sample sizes rounded to nearest 50, following NCES requirements.

Table 35: Wave 2: Frequency NRF last provides child care

\begin{tabular}{lcc}
\hline \hline & No Completed NRQ & Completed NRQ \\
\hline Not Applicable & 0.541 & 0.104 \\
A lot & 0.121 & 0.350 \\
Some & 0.117 & 0.280 \\
Very little & 0.0912 & 0.146 \\
No time & 0.130 & 0.120 \\
Total & 1 & 1 \\
\hline Obs. & 1350 & 650
\end{tabular}

Table 35 displays the response to the question: "In a typical week, does [the child's] father spend a lot, some, very little, or no time taking care of [the child]?", for families without a completed NRQ's (first column) and for those with an NRQ (second column). Sample sizes rounded to nearest 50, following NCES requirements. 
Table 36: Wave 2: Number of Days since NRF last saw child

\begin{tabular}{lcc}
\hline \hline & $(1)$ & $(2)$ \\
& No NRQ & Completed NRQ \\
\hline Don't Know & 0.01 & 0 \\
Refused & 0.01 & 0 \\
Not Applicable & 0.06 & 0 \\
Less than 1 month & 0.459 & 0.896 \\
More than 1 month, less than 1 yr & 0.238 & 0.0718 \\
More than 1 yr & 0.0975 & 0.0198 \\
No contact since birth/separation & 0.133 & 0.0118 \\
Total & 1 & 1 \\
\hline Obs. & 1350 & 650 \\
\hline
\end{tabular}

Table 36 compares the amount of time since non-resident fathers last saw their child, by response status to the non-resident father questionnaire. Sample sizes rounded to nearest 50, following NCES requirements. 
Table 37: Wave 2: Mother's Opinion of Father's Influence on CC

\begin{tabular}{lcc}
\hline \hline & $\begin{array}{c}(1) \\
\text { No NRQ }\end{array}$ & $\begin{array}{c}(2) \\
\text { Completed NRQ }\end{array}$ \\
\hline Not Applicable & 0.373 & 0.0207 \\
No Influence & 0.341 & 0.395 \\
Some Influence & 0.138 & 0.260 \\
A Great Deal of Influence & 0.148 & 0.324 \\
Total & 1 & 1 \\
\hline Obs. & 1400 & 650 \\
\hline \hline
\end{tabular}

Table 37 tabulates mother's responses to the question: "When it comes to making major decisions, please tell me if [child's] father has no influence, some influence, or a great deal of incluence on such matters as child care?", by response status for the nonresident father questionnaire. Sample sizes rounded to nearest 50, following NCES requirements.

Table 38: Wave 2: NRQ Father's Opinion of Father's Influence on CC

\begin{tabular}{lc}
\hline \hline & Frequency \\
\hline Not Ascertained & 0.0318 \\
No Influence & 0.146 \\
Some Influence & 0.328 \\
A Great Deal of Influence & 0.494 \\
Total & 1 \\
\hline Obs. & 650 \\
\hline \hline
\end{tabular}

Table 38 tabulates the response of father's who completed the non-resident father questionnaire to the question "When it comes to making major decisions, please tell me if you have has no influence, some influence, or a great deal of incluence on such matters as child care?". Sample sizes rounded to nearest 50, following NCES requirements. 